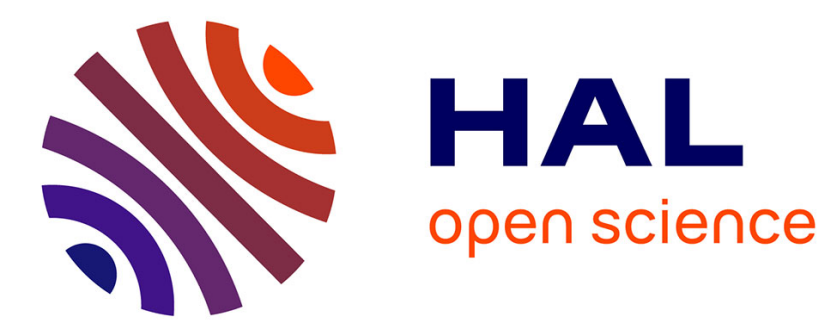

\title{
Vanadium haloperoxidases: from the discovery 30 years ago to X-Ray crystallographic and V K-edge absorption spectroscopic studies
}

C Leblanc, H Vilter, J.-B Fournier, L Delage, P Potin, E Rebuffet, G Michel, P.-L. Solari, Mc Feiters, M Czjzek

\section{To cite this version:}

C Leblanc, H Vilter, J.-B Fournier, L Delage, P Potin, et al.. Vanadium haloperoxidases: from the discovery 30 years ago to X-Ray crystallographic and V K-edge absorption spectroscopic studies. Coordination Chemistry Reviews, 2015, The Ninth International Symposium on the Chemistry and Biological Chemistry of Vanadium, 301-302, pp.134-146. 10.1016/j.ccr.2015.02.013 . hal-01121900

\section{HAL Id: hal-01121900 https://hal.sorbonne-universite.fr/hal-01121900}

Submitted on 2 Mar 2015

HAL is a multi-disciplinary open access archive for the deposit and dissemination of scientific research documents, whether they are published or not. The documents may come from teaching and research institutions in France or abroad, or from public or private research centers.
L'archive ouverte pluridisciplinaire HAL, est destinée au dépôt et à la diffusion de documents scientifiques de niveau recherche, publiés ou non, émanant des établissements d'enseignement et de recherche français ou étrangers, des laboratoires publics ou privés. 
V9 special issue of Coordination Chemistry Reviews

\title{
Vanadium haloperoxidases: from the discovery 30 years ago to $X$-Ray crystallographic and V K-edge absorption spectroscopic studies
}

\author{
C. Leblanc ${ }^{1,2}$, H. Vilter ${ }^{3}$, J.-B. Fournier ${ }^{1,2}$, L. Delage ${ }^{1,2}$, P. Potin ${ }^{1,2}$, E. Rebuffet ${ }^{1,2,6}$, G. \\ Michel $^{1,2}$, P. L. Solari ${ }^{4}$, M. C. Feiters ${ }^{5}$, M. Czjzek $^{1,2}$
}

${ }^{1}$ Sorbonne Universités, UPMC Univ Paris 06, UMR 8227, Integrative Biology of Marine Models, Roscoff, France.

${ }^{2}$ CNRS, UMR 8227, Integrative Biology of Marine Models, Roscoff, France.

${ }^{3}$ Zurmaiener Straße 16, D-54292 Trier, Germany

${ }^{4}$ Synchrotron SOLEIL, L'Orme des Merisiers, Saint Aubin BP48, 91192 Gif-sur-Yvette Cedex, France.

${ }^{5}$ Dept. Organic Chemistry, Inst. for Molecules and Materials, Radboud University, Nijmegen, The Netherlands.

Corresponding Author: Catherine Leblanc

Email: leblanc@sb-roscoff.fr

Phone Number: 33 (2) 982923 62; Fax Number: 33 (2) 98292324

Postal address: UMR 8227, Station Biologique de Roscoff, CS 90074, F-29688 Roscoff CEDEX, France

\section{Present/permanent address:}

${ }^{6}$ Inserm U1068, Centre de Recherche en Cancérologie de Marseille, Institut Paoli-Calmettes, CNRS, UMR7258, Aix-Marseille University UM105, Marseille, France. 


\begin{abstract}
In the environment, vanadium-dependent haloperoxidases (VHPO) are likely to play a key role in the production of biogenic organo-halogens. These enzymes contain vanadate as a prosthetic group, and catalyze, in the presence of hydrogen peroxide, the oxidation of halide ions $\left(\mathrm{Cl}^{-}, \mathrm{Br}^{-}\right.$or $\left.\mathrm{I}^{-}\right)$. They are classified according to the most electronegative halide that they can oxidize. Since the first discovery of a vanadium bromoperoxidase in the brown alga Ascophyllum nodosum thirty years ago, structural and mechanistic studies have been mainly conducted on two types of VHPO, chloro- and bromoperoxidases, and more recently on a vanadium-dependent iodoperoxidase. In this review, we highlight the main progress obtained on the structure-function relation of these proteins, based on biochemistry, crystallography and X-ray absorption spectroscopy (XAS). The comparison of 3D protein structures of the different VHPO helped identify the residues that govern the molecular mechanisms of catalysis and specificity of VHPO. Vanadium K-edge XAS gave further important insight to understand the fine changes around the vanadium cofactor during the catalytic cycle. The combination of different structural approaches, at different scales of resolution, shed new light on biological vanadium coordination in the active site, and its importance for the catalytic cycle and halide specificity of vanadium haloperoxidases.
\end{abstract}

\title{
Keywords (max 6)
}

Vanadium-dependent haloperoxidase, vanadium coordination, crystallographic structure, structural evolution, oligomeric state, X-ray absorption spectroscopy on biological vanadium 


\section{Contents}

1. Introduction

2. Biochemical and molecular characterization of vanadium haloperoxidases

2.1. On the discovery of vanadium-dependent haloperoxidases in the brown alga Ascophyllum nodosum

2.2 Biochemical characterization of vanadium haloperoxidases

2.2.1 Haloperoxidase in vitro assays

2.2.2. Biochemical coordination of $\mathrm{V}$ in vanadium haloperoxidases

2.2.3 Vanadium haloperoxidase - catalyzed halogenation

2.3. Phylogenetic relationships of vanadium haloperoxidases

3. Structure/function of vanadium haloperoxidases

3.1. 3D crystallographic structures and quaternary arrangement of vanadium haloperoxidases

3.2. Similarities between vanadium haloperoxidases and acid phosphatases

3.3. VO4 coordination into crystal structure of vanadium haloperoxidases

4. Biological V K-edge X-ray absorption spectroscopy

4.1. Introduction to BioXAS and other biological V XAS results.

4.1.1 X-ray absorption spectroscopy

4.1.2. Biological vanadium accumulation

4.2. Vanadium and other edge EXAFS and XANES of vanadium haloperoxidases

4.2.1. Early haloperoxidase XANES results

4.2.2. Haloperoxidase EXAFS

4.2.3. Outlook: merging XANES and EXAFS

5. Conclusions and future prospects

Acknowledgements

References 


\section{Introduction}

In Nature, many organic compounds incorporate halogen atoms, which is often an essential step for the biological properties of halogenated antibiotics, drugs or signaling molecules [1]. Halogenated natural products are most commonly chlorinated or brominated, while iodinated and fluorinated compounds are rare, and all structural classes of chemicals are represented, from simple phenolic and aliphatic compounds, to complex alkaloids, polyketides and oligopeptides [2,3]. A large majority of the biogenic halogenated compounds have been isolated in marine organisms, especially marine macroalgae, which seem to be important actors of iodine and bromine transfers in the coastal marine environment [4-6]. Among halogenating enzymes, haloperoxidases utilize hydrogen peroxide for electrophilic halogenation, via the oxidation of halides according to the following reaction: $\mathrm{H}_{2} \mathrm{O}_{2}+\mathrm{X}^{-}+\mathrm{H}^{+}$ $\rightarrow \mathrm{H}_{2} \mathrm{O}+\mathrm{HOX}$, wherein $\mathrm{X}^{-}$represents a halide ion and may be $\mathrm{Cl}^{-}, \mathrm{Br}^{-}$or $\mathrm{I}^{-}$. Haloperoxidases have been classified in two groups, according to the nature of their cofactor, vanadium or heme (iron-containing porphyrin) [1, 7-10]. Metal-free haloperoxidases have also been described in some bacteria [11]. Since the discovery of the first heme haloperoxidase, in the 1960s, from the terrestrial fungus Caldariomyces fumago [12] a number of other heme haloperoxidases have been characterized [1,9]. In this review, we focus on the second important group of haloperoxidases, the vanadium-dependent haloperoxidases (VHPO). In marine algae, these enzymes could be involved in anti-oxidant protection and in chemical defense and are likely to have a key role in the biochemical part of the iodine and bromine cycling in marine environment $[13,14]$. Starting with their discovery thirty years ago [15], this review highlights the main progress that has been obtained on the biochemistry and on the global and fine structural characteristics of VHPO, based on molecular cloning, crystallography and X-ray absorption spectroscopy (XAS). They are classified according to the most electronegative halide that they can oxidize, i.e. chloroperoxidases (VCPO) can catalyze the oxidation of chloride as well as of bromide and iodide, and bromoperoxidases (VBPO) react with bromide and iodide, whereas iodoperoxidases (VIPO) are specific for iodide. Until recently, only chloro- and bromoperoxidases from eukaryotic species have been studied, showing a fragmental view of this large enzyme family. Novel types of VHPO discovered in marine bacteria give now some clues to explore new biosynthetic pathways of natural halogenated compounds through in vitro heterologous expression, but also to further 
study the structure-function relationships in catalytic and specificity mechanisms, and to shed light on VHPO family evolution.

\section{Biochemical and molecular characterization of vanadium haloperoxidases}

\subsection{On the discovery of vanadium-dependent haloperoxidases in the brown alga Ascophylum nodosum}

Interest in peroxidases from brown alga arose in the 1970s, through studies related to the identification of antibiotics from algae reporting that phloroglucinol [16], and then oligomers [17] and polymers of phloroglucinol units [18] were detected in brown algae. These compounds were further characterized as phlorotannins as reviewed in [19]. It was rapidly hypothesized, that peroxidases may be involved in the formation of these phenolic compounds, unique to brown algae. Despite extraction difficulties, due to the complex materials (anionic mucilages containing alginate and fucans), peroxidase-activity was detected in some crude-extract of brown algae, but the enzyme activity was partially lost during the purification process [20]. Intense work finally led to the isolation of the first vanadium-dependent haloperoxidase from knotted wrack, the brown alga Ascophyllum nodosum (Fucaceae, Fucales, Phaeophyta), called AnI in 1984 [15], showing that this enzyme preferentially oxidized iodide and also bromide and thiocyanide in the presence of vanadium (V), but not chloride (reviewed in [21]). The addition of iron and other metal ions had no effect on the activity of the apoenzyme. This algal peroxidase thus was not a hemoprotein, like other iodoperoxidases from plants such as the well-known horseradish peroxidases [22]. Anecdotal, in the 1970s, vanadium was not considered to be an essential element in biology or in medicine, and until 1984, no scientific study has reported that vanadium could be a natural component of any enzyme. Consequently the paper on the vanadium-dependence of this new algal haloperoxidase [15] was not accepted in the first instance. However, since vanadium accumulation has been reported in ascidians in 1911 by Henze [23] experiments to test the effect of vanadium compounds were proposed by Vilter and coworkers. Indeed H. Vilter had observed an effect when solutions were aliquoted using a Hamilton syringe that brought the solutions in contact with vanadium-containing steel. Inspired by these effects, significant increase in haloperoxidase activity was observed in subsequent experiments using vanadate- 
containing buffers. At that time, the detection of a vanadium-containing nitrogenase was also reported $[24,25]$. In 1986, the vanadate cofactor was finally confirmed for the vanadiumdependent haloperoxidase from A. nodosum [26] and for the alternative nitrogenase in Azotobacter chroococcum [27]. In parallel, several reports indicated that vanadium was indeed an essential trace element for animals [28], Chlorella [29-32], Enteromorpha and Fucus [33]. Since its discovery, $A n \mathrm{I}$ was used as a laboratory model enzyme for the understanding of VHPO properties. Numerous further studies were carried out to characterize the $\mathrm{V}$ coordination inside the active site of AnI (later called An-VBPOI in this review), based on electron paramagnetic resonance [26, 34, 35], on ${ }^{51}$ V NMR [36-38], X-ray crystallography $[39,40]$ and on XAS ([41-43] see below).

\subsection{Biochemical characterization of vanadium haloperoxidases}

Vanadium-dependent haloperoxidases (EC 1.11.1.10) catalyze the two-electron oxidation of halides $\left(\mathrm{X}^{-}: \mathrm{I}^{-}, \mathrm{Br}^{-}\right.$or $\left.\mathrm{Cl}^{-}\right)$in the presence of hydrogen peroxide $\left(\mathrm{H}_{2} \mathrm{O}_{2}\right)$ by a bi-bi ping-pong mechanism. During the catalytic cycle, the vanadate cofactor, at the resting (V) state, first coordinates one molecule of $\mathrm{H}_{2} \mathrm{O}_{2}$ to form a stable peroxovanadate intermediate, which can then react with halide. After halide oxidation, the electron oxidized halogen intermediate " $\mathrm{X}$ ", which is a mixture of different halogen species such as $\mathrm{OX}^{-}, \mathrm{X}_{3}{ }^{-}$or $\mathrm{X}_{2}$, may rapidly halogenate organic substrates in a non-enzymatic reaction (Scheme 1). In the absence of organic substrate, a second equivalent of $\mathrm{H}_{2} \mathrm{O}_{2}$ is oxidized to form a single oxygen and $\mathrm{X}^{-}$[for reviews $\left.1,7,8,10,44\right]$.

\subsubsection{Haloperoxidase in vitro assays}

For kinetic studies, vanadium and heme haloperoxidases differ from other enzymes by the production of this very reactive and undetectable intermediate " $\mathrm{X}^{+}$". Standard assays for the determination of VHPO activity are therefore based on the reactivity of this mixture with commercial chemicals. Phenol red and $o$-dianisidine were first reported as chemical probes for the detection of VHPO-catalyzed halogenation, but are restricted to qualitative studies [4547]. The monochlorodimedone (MCD) halogenation provides a simple assay to determine steady-state kinetic parameters of VCPO and VBPO at acidic pH by monitoring the loss of absorbance of MCD at $290 \mathrm{~nm}$ [48-50]. The triodide $\left(\mathrm{I}_{3}{ }^{-}\right)$assay (reviewed in [21]) was used to identify the first VIPO, i.e. specific for iodide oxidation, in brown algae of the Laminariaceae 
family [51-54]. However, this assay presents important limits due to the high chemical instability of $\mathrm{I}_{3}{ }^{-}$in solution. For this reason, a colorimetric assay was later developed for the titration of both iodo- and bromoperoxidase activities based on the reactivity of thymolsulfonephthalein, also named thymol blue (TB) toward oxidized bromide and iodide species [55]. Using this assay, novel VIPO were recently characterized in the marine bacteria Zobellia galactanivorans [56].

\subsubsection{Biochemical coordination of $\mathrm{V}$ in vanadium haloperoxidases}

Vanadate $\left(\mathrm{VO}_{4}\right)$ is the prosthetic group of VHPO and its incorporation into the enzyme is necessary for the catalytic activity. Indeed the apoenzymes, produced through dialysis, feature a drastic decrease of activity, while the reconstitution of VHPO with aqueous sodium orthovanadate leads to progressive and full recovery of haloperoxidase activity [15, $35,57-60]$. The ratio of vanadate per protein subunit was estimated around one $\mathrm{VO}_{4}$ per subunit, but was lower in VBPOII from A. nodosum [60]. The affinity of VHPO for vanadate depends on $\mathrm{pH}[15,61,62]$, and is much stronger than for oxyanions, such as phosphate or molybdate $\left(\mathrm{HVO}_{4}{ }^{2-}>>\mathrm{HPO}_{4}{ }^{2-}>\mathrm{AsO}_{4}{ }^{3-}>\mathrm{MoO}_{4}{ }^{2-}\right)[34,61]$. However, the peroxidase activity decreases in phosphate-containing buffers [21].

Unlike the heme-containing enzymes, there is no change in the oxidation state of the VHPO metal center during the synthesis of the halogenating agent, making them insensitive to oxidative inactivation during turnover. VHPO enzymes are also extremely thermostable, resistant to high concentration of organic solvents such as methanol, ethanol, 1-propanol, acetone [45] and dioxane and still active in concentrated solutions of guanidine hydrochloride or SDS $[61,63]$.

\subsubsection{Vanadium haloperoxidase - catalyzed halogenation}

Because of their biochemical properties, VHPO have received increasing attention as biocatalysts for pharmaceutical and biotechnological applications [44, 64]. The halogenation mechanism of VHPO is still debated for unspecific diffusible species-mediated halogenation versus specific halogenation of substrate into the active site. The main bottleneck for deciphering the biochemical role of an enzyme is to find its natural organic substrate. The specific halogenation patterns in natural organohalogens suggest that VHPO catalysis is stereo- and regio-selective in vivo [64]. However, only few reports are available about the chemical characterizations of natural substrates, deduced from VHPO-based halogenation in vitro. Data are indeed restricted to either purified native VHPO, as those from A. nodosum 
$[44,60]$, or to recombinant active enzymes, which have been successfully over-expressed in E. coli [65-67], in yeast system [58,59], or in other heterologous systems [68-70] (see Table 1 for complete references).

VHPO activities have been detected in a very large number of marine macroalgal classes using MCD or $\mathrm{I}_{3}{ }^{-}$assays [21], but the corresponding biochemical data are very limited in early studies because of the difficulties to purify such enzymes from algal matrices extremely rich in anionic polysaccharides and polyphenolic compounds. The problem was solved by developing two-phase extraction procedures, and brown algal peroxidases were obtained in gram-amounts [20]. Up to now, a number of VHPOs have been characterized at the biochemical and molecular levels from red and brown macroalgae, terrestrial fungi and marine bacteria (see Table 1 for complete references). In the brown alga A. nodosum, the two VBPO isoenzymes present at different locations in the alga $[61,71]$ feature distinct biochemical and structural properties [60], suggesting distinct biological roles in the algal physiology. In vitro halogenation experiments have shown that purified native VBPOI from A. nodosum catalyzes the bromination of pyrroles [72] or phenols [73], whereas the second VBPO is involved in the biosynthesis of methyl 4-bromopyrrole-2-carboxylate, a natural product isolated from the marine sponge [60]. Laminaria digitata also features two isoforms of VHPOs, but with distinct halide specificities. One is a VBPO [53], whereas the other isoform is specific for iodide oxidation [54]. No specific iodinated substrate has been yet identified in L. digitata, but this particular VHPO may be involved in the very efficient accumulation of iodide in external tissues of L. digitata [14, 74, 75]. Another VIPO was recently characterized at the structural level in the marine flavobacterium Z. galactanivorans, which belongs to the bacteroidetes and is associated with both red and brown seaweeds [56].

In red algae (Table 1), VBPO were isolated from Corallina officinalis and Corallina pilulifera [76-79], and more recently VBPO from Delisea pulchra [80] and from Gracilaria changii [81]. The VBPO-catalyzed asymmetric bromination and cyclization of certain terpenes, including nerolidol, lead to the biosynthesis of brominated cyclic sesquiterpenes. This was established in vitro by VBPO isolated or cloned from Laurencia, Plocamium and Corallina [82]. The VBPO from Delisea pulchra produces bromofuranones, which are involved in the disruption of quorum sensing of epiphytic bacterial biofilms [80]. Algal halogenated compounds are known to interfere with bacterial signaling systems. Similarly, VBPO from L. digitata can deactivate acylated homoserine lactones, which are the cell-to-cell 
signaling molecules. Moreover halogenated compounds from this species control the biofilm formation and growth in Gram-negative bacteria [83, 84].

VCPO were first characterized in terrestrial fungi, the most studied being that of Curvularia inaequalis ([85], Table 1 for full references). The fungus $C$. inaequalis is able to chlorinate aromatic rings of lignin in wood during the degradation process and this action is likely to be due to the presence of VCPO enzymes [86]. The VHPO-based biofilm control has been also explored for medical purposes: VCPO from $C$. inaequalis has an antimicrobial action on Enterococcus faecalis biofilms [87].

VCPOs were also identified in marine actinobacteria [68, 88]. Another class of interesting compounds is that of halogenated antibiotics. Interestingly, bromoperoxidase activity was first detected in the chloramphenicol-producing actinomycetes [89]. In Streptomycete bacteria, a VCPO, encoded by the NapHI gene, catalyzes a highly stereoselective chlorination cyclization reaction in napyradiomycin biosynthesis [68, 88]. More recently in vitro biosynthetic experiments established the roles of VCPO from the marine bacterium Streptomyces sp. strain CNH-189 in the final chlorination cyclization step of the merochlorin biosynthesis. The existence of a highly regiospecific and stereospecific reaction in this synthesis of chlorinated antibiotics suggests that in vivo the VHPO bind their natural substrates in a highly specific manner $[69,70]$.

\subsection{Phylogenetic relationships of vanadium haloperoxidases}

VHPO share a relatively low level of overall protein sequence identity. For instance, the fungal VHPO from C. inaequalis [85] and Alternaria didymospora [90] present a protein sequence identity of $68 \%$, and the protein sequence identities between VHPO from brown and red algae are only in the range of 30 to $40 \%$. At the protein level, only one hundred amino acid residues from the carboxyl terminal regions of the fungal enzymes can be aligned with VHPO from macroalgae, with $\sim 25 \%$ of similarities. This alignment bears the two following short domains highly conserved in all VHPO proteins and related to vanadate binding (see below).

\section{(1) PxYxSGHA

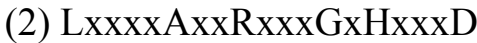

A phylogenetic analysis based on the alignment of 26 biochemically- and/or structurally-characterized VHPO (Table 1) was carried out, including four sequences of 
bacterial nonspecific acid phosphatases as outgroup [7, 56]. In this phylogenetic tree (Figure 1) the VHPOs from red and brown algae group together with some VBPOs from Cyanobacteria, suggesting a common origin of all algal VHPOs. Inside the brown algal VHPO sub-group, two branches appear, one including the first VBPO of A. nodosum and the VIPO from $L$. digitata and the other bearing the second isoform of A. nodosum and the VBPO of L. digitata [56]. The red algal VBPOs form a strong monophyletic group with few cyanobacterial VHPO homologous proteins, one of which has recently been characterized as VBPO in a Synechococcus strain [91]. In the other part of the tree (Figure 1) the VIPO from Z. galactanivorans, the fungal VCPO, including that of $C$. inaequalis, and the first bacterial VCPOs characterized in Streptomyces species merge as different monophyletic groups. A recent larger phylogenetic analysis allowed the identification of numerous VHPO bacterial homologs in public protein databases, suggesting a larger spreading of VHPO in bacterial lineages and a significant bacterial contribution to VHPO-mediated processes [56]. Based on phylogenetic analyses VHPO could derive from a common marine bacterial ancestor, closely related to bacterial acid phosphatases, and their evolution may have been driven by successive lateral transfer events. Moreover the specificity for iodide oxidation results in a convergent evolution of the divergent phyla of bacteroidetes and brown algae [56].

\section{Structure/function of vanadium haloperoxidases}

\subsection{D crystallographic structures and quaternary arrangement of vanadium haloperoxidases}

In 1996, Messerschmidt and Wever published the first crystallographic structure of a vanadium dependant haloperoxidase, which was the chloroperoxidase isolated from the fungus Curvularia inaequalis [92]. The overall shape of the monomeric protein has the form of a cylinder of about $80 \AA$ long and $50 \AA$ in diameter (Figure $\mathbf{2 A}$ ). The fold is compact with about $44 \%$ of the residues involved in alpha-helices. The helices form two main domains consisting of a helix-bundle each that are related by a pseudo-2-fold axis perpendicular to the axes of the helices. The two helix-bundles are often called bundle 1 and 2, in relation to their occurrence in the $\mathrm{N}$ - or $\mathrm{C}$ - terminal part of the enzyme, respectively. The site of fixation for 
vanadate is located at the bottom of a $20 \AA$ deep cavity, situated at the $\mathrm{N}$-terminal ends of helices from bundle 2 (Figure 2A-B).

A few years after this first structural characterization of a fungal VHPO, structures of a VBPO of algal origin were published (see Table 1 for full references), revealing complex multimerization of these latter ones. Indeed, the first characterized VBPO from the brown alga $A$. nodosum is arranged in dimers, stabilized by two disulfide bridges covalently linking the two monomers (Figure 2C) [39]. These dimers are able to self-arrange in more complex structures, such as hexameric proteins, as shown by gel filtration chromatography results obtained for VBPO from L. digitata [53] and for the second VBPO from A. nodosum [60]. In contrast, the red algal VHPO dimers are not stabilized by covalent bonds but organized in a hexamer of dimers (Figure 2D) [93, 94]. This dodecamer is about $150 \AA$ in diameter and forms a cavity in its center. This multimeric complex also presents a high degree of 2-3-point group symmetry that is cubic. Interestingly, so far in all characterized algal VHPOs, the Nterminal helix-bundle is structurally replaced by the C-terminal helix-bundle of a second monomer in the homo-dimeric protein, with the two molecules arranged in a 'head-to-tail' orientation. Multimerization is a biological strategy to stabilize proteins [95]; consequently, in the case of red algal VHPOs, the high stability to organic solvent and high temperature might be a result of the strong interactions present in these highly symmetric multimers. In VBPO dimers, the surface of interaction represents 20 and $46 \%$ of the total exposed surface of a monomer for C. officinalis [93] and A. nodosum [39], respectively. In contrast, in the red algal VBPO dodecamer, only $12 \%$ of a monomer surface is exposed to the solvent $[93,96,97]$.

More recently, 3D structures from bacterial VHPOs (Table 1), the VCPO from Streptomyces sp. (Liscombe et al., unpublished) and the VIPO from the marine flavobacterium Z. galactanivorans [56] have shed new light on plausible evolutionary relationships between algal multimeric forms and fungal and bacterial monomeric forms of VHPOs. Indeed, the two bacterial VHPOs are similar to the monomeric fungal VCPO, consisting of two helix-bundle domains within a single polypeptide chain in the VIPO from $Z$. galactanivorans (Figure 2B). Despite this fold-similarity, the Z. galactanivorans VIPO is a monomer in solution, while VCPO of Streptomyces sp. is dimeric. However, the dimerization mechanism in this latter case is very different to that found in algal VHPOs, and probably carries a different biological function. The Streptomyces sp. VCPO dimer-interface is located above the N-terminal helix-bundle, where two small (3 to 4 residues) beta-strands form an anti-parallel beta sheet. The longest beta-strand of each monomer interacts with the equivalent 
one in the second monomer, in an anti-parallel manner, and together they create an interface much smaller than that observed in the complex multimeric algal VHPOs.

As explained above, the vanadium containing active site of VHPOs is located at the Nterminal end of helices from bundle 2 in fungal and bacterial VHPOs (Figure 2A-B), , and two residues within the second ligand sphere of the $\mathrm{VO}_{4}{ }^{3-}$ are provided by the helix bundle 1 . This vanadium binding site structure is perfectly conserved throughout all VHPOs (see below), despite the fact that the algal VHPO lack the helix bundle 1. Indeed the missing helices are replaced by the second monomer in the dimeric forms of VHPOs. Nevertheless, all VHPOs have roughly the same number of residues, between 450 and 550 amino acids. Indeed, algal VHPOs display several additional insertions, forming helices and beta-strands that are not present in the fungal or bacterial VHPOs [56]. The comparison of all the known haloperoxidase structures shows that a fungal or bacterial VHPO monomer can be superimposed onto the dimer of an algal VHPO, with the N-terminal helix-bundle 1 of the single peptide chain in the monomeric forms being replaced by the 'back-side' of the Cterminal helix-bundle belonging to the second chain of the homodimeric form (Figure 2C). This observation, combined with phylogenetic analyses, has allowed postulating a bacterial origin of the ancestral VHPO with a monomeric conformation [56]. In this scenario the loss of helix bundle 1 in algal VHPO, has probably been the key to dimerization: an incomplete gene transfer leading to the deletion of helix bundle 1 exposes a hydrophobic patch at the surface of the protein, necessitating the replacement of this part of the fold by a helix bundle from a second monomer, thus facilitating the dimerization. The dimerization leads to the interesting feature that the homodimeric algal VHPOs have two vanadate-containing active sites, whereas the fungal and bacterial monomeric forms only possess one active site per protein.

\subsection{Similarities between vanadium haloperoxidases and acid phosphatases}

In monomeric VHPOs the two domains of the same protein, the conserved C-terminal helix-bundle and variable N-terminal helix-bundle, can be superimposed on each other at the structural level (Figure 3A), despite the fact that no similarity can be detected between the two helix bundles at the level of primary sequence. Interestingly, the 3D structural fold of acid phosphatases, represented through the monomer structure of a non-specific acid phosphatase from Escherichia blattae [98] is constituted by a single helix-bundle motif. Indeed, when structurally superimposing the five-helix-bundle of an acid phosphatase onto monomeric VHPOs, stronger similarity can be observed with the conserved C-terminal helix-bundle 
domain than when superimposing onto the variable N-terminal helix-bundle of VHPOs (illustrated by the superimposition onto the C-terminal helix-bundle of Zg-VIPO1 in Figure 3B). This structural domain homology to acid phosphatases has been previously identified by the comparison to Ci-VCPO [98-100]. Together with phylogenetic analyses [56], these 3D fold-similarities suggest that acid phosphatases and VHPOs have a common ancestor with an ancestral fold consisting of a single helix-bundle-based core domain, and VHPOs have diverged from this ancestor fold by gene-duplication followed by gene-fusion. In this scenario, the presence of additional ligands provided by the second helix-bundle has led to the fixation of catalytic active vanadate rather than phosphate. However, we can not rule out that ancestral active VHPOs contain only a single helix bundle that have then diverged into two distinct forms, either by dimerization or by gene-duplication followed by gene-fusion. In any case, this evolutionary relationship between phosphatases and VHPOs has some functional consequences: since the phosphate and vanadate binding sites are sufficiently similar, it has been demonstrated that the apo-form of VCPO exhibits phosphatase activity [101], whereas the phosphatases are strongly inhibited by vanadate [102]. In several 3D structures, bound phosphate was located in VHPOs in a similar manner than the vanadate group, either in the native Ci-VCPO [92] or in the VBPO of Corallina species [93, 94, 103]. This oxyanion is only weakly linked to the $\mathrm{N}^{\varepsilon}$ atom of the histidine residue, but a systematic comparison of phosphate- and vanadate-binding proteins in the protein data bank shows high structural similarities and similar binding [104].

\section{3. $\mathrm{VO}_{4}$ coordination in the crystal structure of vanadium haloperoxidases}

When studying the molecular bases of catalytic properties and halide specificity in VHPO, it is of interest to compare the $3 \mathrm{D}$ active site structures of the different types of VHPO, i.e. the fungal and bacterial VCPO, the algal VBPO, and the recently discovered VIPO from Z. galactanivorans [56]. The active site pockets of the different VHPOs display strong similarities, despite the different oligomeric forms of enzymes, and most of the residues tightly coordinating the catalytic vanadate are strictly conserved within $\mathrm{C}$-terminal helix bundle (Figure 4), the active site pocket being also delimited by the neighboring Nterminal helix bundle in fungal and bacterial VHPOs and by the C-terminal helix bundle from the second monomer in algal VHPOs (Figure 2).

The $\mathrm{N}^{\varepsilon}$ group of a strictly conserved histidine (His416, His496, His494, His486, His553 and His553 in Zg-VIPO1, Ci-VCPO, Ssp-VCPO, An-VBPOI, Co-VBPO and Cp-VBPO, 
respectively, Figure 4A-F) is binding the vanadate, providing the fifth atom in the trigonalbipyramidal coordination sphere of vanadium (V). As mentioned above, the VO4 binding in VHPOs also corresponds to the assumed trigonal bipyramidal transition state of bound phosphate in the phosphatases [104]. All other ligand-atoms of the vanadium-ion are the four oxygens from the prosthetic group. These oxygen atoms are in turn hydrogen bonded by a lysine, a serine, a histidine and two arginine residues that are all conserved, with one exception, viz. the replacement of the histidine (His360 in Zg-VIPO1, Figure 4A) by a serine in the bacterial VCPO (Ser427, Figure 4C).

For the VCPO from the fungus $C$. inaequalis the X-ray structures of both native and peroxide forms of the enzyme have been solved at $2.03 \AA$ and $2.24 \AA$, respectively [105]. These two structures have revealed that the trigonal bipyramidal geometry of the vanadate in the native form is transformed in a distorted tetragonal pyramid after addition of hydrogen peroxide, suggesting the release of the apical oxygen ligand and the coordination of the two peroxide oxygens to the vanadium cofactor in the stable peroxide form of the enzyme ([105], see Scheme 1). During the catalytic cycle, at least the histidine and one arginine (His360 and Arg410 in Zg-VIPO1, Figure 4A) are essential residues for the coordination of the vanadate moiety and catalysis, since changing them into alanine or serine totally switched off haloperoxidase activity in Ci-VCPO [58, 106] and in Zg-VIPO1 [56]. In the VCPO from Streptomyces sp., the serine residue (Ser427) seems to play a similar role, as its mutation in a histidine residue abolished enzyme activity [68].

Another remarkable difference in the bacterial VCPO and in all algal VBPOs is the presence of an additional histidine, in the proximity of Lys341 (An-VBPOI numbering, Figure 4D) that is replaced by a phenylalanine in the fungal VCPO. Based on the first few available crystal structures [39, 92-94, 103], it was postulated that this single residuedifference between vanadium-dependent chloro- and bromoperoxidases, i.e. a Phe397 in VCPO (Figure 4B) replacing a histidine residue in VBPO, was responsible for the difference in halogen specificity [66]. Previously, the mutation of the arginine residue (Arg397) in the red algal VBPO from $C$. pilulifera (Figure 4F) has conferred significant chloroperoxidase activity to mutant enzymes R397W and R397F [94, 107]. This residue is replaced by a tryptophan residue in the fungal VCPO. However, the more recent crystal structure of VIPO, having identical residues in the first coordination sphere of the catalytic vanadate as in VCPO [56] including this phenylalanine, showed that the structural factors governing the oxidation potential of halides in this enzyme family is much more complex. In this latter study, sitedirected mutagenesis of residues located in a second sphere around the active site highlighted 
that some of these could equally well influence the halide-oxidation potential of this enzyme, and even the specificity of the enzyme. Indeed a slight bromoperoxidase activity was obtained in two enzyme mutants, one mutated inside the active site (Ser358, Figure 4A) and the other mutated on a tyrosine residue located outside the active site. The current hypothesis $[7,8,55]$ explains the change of catalytic properties and halide specificity by modifications of $\mathrm{H}$-bond coordination and redox potential of the $\mathrm{VO}_{4}$ moiety, rather than selective halide binding. Recent data suggest that this redox potential is finely tuned locally, but also by remote amino acid residues, belonging to the second and third sphere of $\mathrm{VO}_{4}$ coordination [56].

\section{Biological Vanadium K-edge X-ray absorption spectroscopy}

\subsection{Introduction to BioXAS and other biological Vanadium XAS results.}

\subsubsection{X-ray absorption spectroscopy}

X-ray absorption spectroscopy (XAS) is applied to study the coordination geometry of transition metals in enzymes, as well as changes of geometry during catalysis $[108,109]$. The method can also be applied to non-invasively study halogens in whole organisms [14], parts thereof $[110,111]$, or isolated enzymes [112]. The X-ray absorption spectra of dilute systems (mM in metal) like biological samples are usually measured in fluorescence mode; for vanadium this is relatively difficult compared to other $1^{\text {st }}$-row transition metals, because there is less fluorescence and the K-edge is at low energy, a range where air absorbs significantly. Some examples of vanadium K-edge spectra are shown in Figure 5.

With monochromatic synchrotron radiation, it is possible to scan the X-ray energy around the so-called $\mathrm{K}$ edge of an element, for example vanadium (V). At the absorption edge, the X-ray energy corresponds to what is needed to liberate a $1 \mathrm{~s}$ electron of $\mathrm{V}$ into the continuum. The edge energy shifts to a higher value if the $\mathrm{V}$ is in a higher oxidation state. There is usually some fine structure present in this 'X-ray Absorption Near Edge spectrum' (XANES) which can also be represented as the first derivative in order to highlight subtle features (Figure 5A-B). The fine structure is due to the electron being excited to unoccupied higher orbitals with energies just below that of the continuum; the intensities of such transitions depend on their being allowed or forbidden, which in turn depends on the metal ion's coordination geometry. Above the edge, additional features, the so-called 'Extended X- 
ray Absorption Fine Structure' (EXAFS, Figure 5C) are observed, which are due to X-rayinduced electron diffraction phenomena and can be interpreted in terms of distance, number, and type of the surrounding ligands. The EXAFS is usually displayed with the wave vector $k$ $\left(\AA^{-1}\right)$ as energy axis, and in $k^{3}$-weighting to compensate for the decay in amplitude at higher $k$. The EXAFS amplitude depends on the coordination number but this can only be determined with limited accuracy $( \pm 1)$ because of its correlation with the disorder phenomena, described in the so-called Debye-Waller factor, that are responsible for the aforementioned decay in the amplitude. Fourier transformation (with phase correction) of the EXAFS (FT, Figure 5D) yields a radial distribution function in which the positions of the maxima represent the distances of shells of ligand atoms to the absorber atom, which can be determined fairly accurately (typically $\pm 0.02 \AA$ ). Atom types differ in backscattering amplitudes and in the phase relationship between EXAFS and Fourier transforms; atoms of the same row in the Periodic Table are so similar that they cannot easily be distinguished ( $Z$ determined to an accuracy of \pm 1 ). Ligands like the imidazole moiety of the amino acid histidine give a characteristic pattern of shells for which the multiple scattering phenomenon, i.e. the scattering of the electron wave by various ring atoms before it returns to the $\mathrm{V}$ absorber, has to be taken into account in the simulation. The interpretation of EXAFS is performed by means of simulation on the basis of parameters of structural models which are iteratively refined to give the optimum agreement between theory and experiment as expressed in a fit index.

\subsubsection{Biological vanadium accumulation}

Because of the relatively high concentration requirements it is not surprising that the first example of a study of vanadium in a biological context was on organisms that actively accumulate vanadium from seawater, in the form of vanadate $\left(\mathrm{V}(5+) \mathrm{O}_{4}{ }^{3-}\right)$, viz. of the aforementioned ascidians [23], a class belonging to the phylum of tunicates [113]. The XANES of these organisms, when compared to that of suitable model compounds, showed that the vanadium was predominantly in the $\mathrm{V}(3+)$ state in an octahedral environment, while the EXAFS revealed the nearest neighbours to be oxygens. In subsequent studies, the $V$ XANES features were used to quantify the amounts of $\mathrm{V}(3+)$ ions associated with the biological catecholate-based chelator tunichrome, and water and sulphate, as well as mixtures of the latter in various species [114-118], and a detailed mechanism for the reduction of vanadate to $\mathrm{V}(3+)$ was proposed [119]. In this particular context, the role of sulphur in the vanadium metabolism was also investigated with sulphur K edge XANES [120-122]. Micro- 
distribution of $\mathrm{V}$ was established in living ascidian blood cells by X-ray scanning microscope in fluorescence mode and local XANES spectra revealed $\mathrm{V}(3+)$ and $\mathrm{V}(4+)$ in vivo [123]. With X-ray tomography in combination with X-ray fluorescence, three-dimensional maps of the element distribution in objects and biological specimens such as the diatom Cyclotella can be obtained [124]. With scanning X-ray microscopy, it is possible to record short ranges XANES rather than EXAFS - of X-ray spectra at the edge of an element, and combine them with the image, to map the distribution of that element's oxidation state. This is an interesting approach for vanadium because of the sensitivity of its XANES to oxidation state and ligand geometry. In applications [125-126] of this technique in relation to the aforementioned biological vanadium accumulation, a scanning X-ray microscopy study of cryo-fixed specimens of one type of blood cell - the so-called signet cell - from Ascidia sydneiensis samea, it was shown that the reduction of $\mathrm{V}(5+)$ from seawater proceeds in 2 steps, viz. to $\mathrm{V}(4+)$ in the signet ring cells, and to $\mathrm{V}(3+)$ in the vacuole. One other occurrence of vanadium in a biological context, besides that of $\mathrm{V}$ in haloperoxidases, is that in aforementioned vanadium-dependent nitrogenases $[28,127]$. The XANES and EXAFS at the V K-edge of the first V-containing nitrogenase from A. chroococcum resembled very much that of a $\mathrm{VFe}_{3} \mathrm{~S}_{4}$ cubane cluster [128].

\subsection{Vanadium and other edge EXAFS and XANES of vanadium haloperoxidases}

\subsubsection{Early vanadium haloperoxidase XANES results}

Studies on the vanadium-containing haloperoxidases started with XANES of the brown alga A. nodosum bromoperoxidase [41]. The prominent pre-edge peak at $5469 \mathrm{eV}$ (Figure 5A) is ascribed to a $1 \mathrm{~s}-3 \mathrm{~d}$ transition which is dipole-forbidden and absent in octahedral VO [129] but very strong in tetrahedral vanadate (Figure 5A). For the native bromoperoxidase of $A$. nodosum, the feature is somewhat weaker than for vanadate (Figure $\mathbf{5 A},[42])$ which is consistent with the trigonal bipyramidal coordination symmetry established in the crystallographic study [39]. A similar change was observed in the XANES of vanadate upon binding to the chloroplast $\mathrm{H}^{+}$-ATPase CF1 together with $\mathrm{Mg}^{2+}$ and ADP; this creates an enzyme-bound transition-state analogue for ATP-hydrolysis in which the V has trigonalbipyramidal coordination geometry [130].

The haloperoxidase XANES is not affected by addition of the substrate $\mathrm{Br}^{-}$(90 molar equivalents), but upon reduction the edge shifts to lower energy and the pre-edge feature is 
reduced in intensity [42]. Addition of 4 molar equivalents of $\mathrm{H}_{2} \mathrm{O}_{2}$ had no effect [42] but a significant shift of the edge to lower energy and a subtle increase in the pre-edge feature were observed with 15 molar equivalents [43]. These changes point respectively to an increase in average $\mathrm{V}$-ligand distance and to a change in symmetry, but not to a change in oxidation state for V. Accordingly, a mechanism was proposed for VHPO-based bromination (Scheme 1) without valence change for $\mathrm{V}$ nor coordination of $\mathrm{Br}^{-}$to $\mathrm{V}$, in which coordination to $\mathrm{V}(5+)$ activates $\mathrm{H}_{2} \mathrm{O}_{2}$ for attack by bromide, forming the hypobromite which is the halogenating agent.

\subsubsection{Vanadium haloperoxidase EXAFS}

The first haloperoxidase EXAFS was obtained for the native and reduced forms of $A$. nodosum VBPOI in a $k$ range of 3-10 $\AA^{-1}$ [42] at a time when no crystallographic information was yet available. For the reduced enzyme, one short $(1.63 \AA)$ and 3 medium $(1.91 \AA) \mathrm{V}-\mathrm{O}$ distances were identified, along with two V-N distances of $2.11 \AA$, which were inferred to belong to imidazole moieties of histidine residues on the basis of advanced EPR (electron spin echo) studies [43], and simulated as such. The results for the native enzyme were similar, but most distances $(1.61,1.72$, and $2.11 \AA$ ) were shorter, and the more remote atoms were not explicitly assigned to imidazoles but as $\mathrm{N}$ or $\mathrm{O}$. In a later study [131], the distance information was used in a Bond Valence Sum Analysis (BVSA) [132], using known correlations between the valence, ligand distances, and ligand geometry of ions, to correct the coordination number initially found [42] from 6 to 5. If one considers one of the imidazole or $\mathrm{N} / \mathrm{O}$ ligands from the initial interpretation to be redundant in the 5-coordinate geometry, this outcome is consistent with the crystallographic results, first for the VCPO from the fungus $C$. inaequalis [92], later for the A. nodosum VBPO [39], that vanadium in haloperoxidases is present as vanadate, bound to the enzyme by coordination to a single imidazole residue.

Although the imidazole ligand was recognized in the EXAFS of reduced enzyme on the basis of the EPR evidence [133], it was almost overlooked in the native enzyme [42].The aforementioned current structural model for the nitrogenase cofactor FeVco also features imidazole coordination, although this is not detectable in the EXAFS. The crystal structure of the [vanadyl(vinylimidazole) $\left.{ }_{4} \mathrm{Cl}\right] \mathrm{Cl}$ complex revealed $\mathrm{V}-\mathrm{N}$ distances in the range 2.05-2.19 $\AA$, and the imidazoles gave an unambiguous contribution to the EXAFS in the Fourier transform (radial distribution function) in the range 2-4 $\AA$, with an average distance of $2.11 \AA$ [134], in line with the V-N distance found in the A. nodosum VBPOI EXAFS [42]. It is clear from the features in the EXAFS in the range 2-4 $\AA^{-1}$ (Figure 5C) that there are remote shells in 
addition to the main shell of oxygen (and nitrogen) ligand donors, atoms that also contribute to the EXAFS, but the corresponding features in the Fourier transform at 3-4 $\AA$ are relatively small (comparable to the intensity for vanadate in that region) if it is taken over a relatively long data range (Figure 5D). Alternative interpretations have been put forward for the remote haloperoxidase shells, such as a shell of protein heteroatoms that are H-bonded to the vanadate [135], and, by analogy to the archaeal tungstate binding proteins [136], throughabsorber multiple scattering involving the axial ligand donor atoms in the trigonal bipyramid, which would appear in the Fourier transform at the sum of the V-N(imidazole) and V$\mathrm{O}($ axial) distances [137].

It was concluded from V EXAFS taken over a relatively short range (up to $k=7 \AA^{-1}$ ) of the A. nodosum VBPOI in the presence of excess ( 3 molar equivalents) bromide that there is no direct $\mathrm{V}-\mathrm{Br}$ interaction (expected distance $2.45 \AA$ ) $[138,139]$. This was corroborated by the absence of such a contribution in the complementary Br EXAFS [140], which instead indicated the presence of $\mathrm{Br}$ covalently bound to a low- $\mathrm{Z}$ atom, then interpreted as due to a putatively reactive $\mathrm{Br}-\mathrm{O}(\mathrm{Ser})$ intermediate. It was later found [112] that the enzyme actually contains endogenous bromine in the form of bis-brominated (3,5-dibromo)-tyrosine residues, presumably due to exposure to both $\mathrm{Br}^{-}$and $\mathrm{H}_{2} \mathrm{O}_{2}$ before or during isolation. Br EXAFS also revealed the presence of bromine incorporated in other amino acids, possibly tryptophan, in the VHPO of L. digitata [110].

As mentioned above, the crystal structures of the native [92] and peroxo [105] forms of the $C$. inaequalis VCPO indicated that two vanadate oxygens are displaced by the peroxide which is bound in a side-on fashion, and that the geometry changes from a trigonal bipyramid with the imidazole- $\mathrm{N}$ in one of the apical positions to a square pyramid with an apical oxygen (see Scheme 1 for a schematic representation of the structures, in which the ellipsoids indicate the equatorial planes). While the XANES of A. nodosum VBPOI showed a significant shift to lower energy with a large excess of $\mathrm{H}_{2} \mathrm{O}_{2}$ (see above) [43], indicating a longer average $\mathrm{V}$ ligand distance, the corresponding spectra for $C$. inaequalis VCPO with 4 molar equivalents of $\mathrm{H}_{2} \mathrm{O}_{2}$ were rather similar. The EXAFS of both enzyme forms was also measured, compared, and analyzed [141] in an approach in which the geometry of the imidazole was constrained [142], i.e. the atom-atom distances within the ring were kept in an idealized geometry, so that the whole imidazole was treated in the refinement of the simulations as a unit. The EXAFS distances agree within $0.1 \AA$ to the crystallographic ones for the native enzyme, but in the peroxo form the crystallography seems to overestimate the V-N and two of the V-O distances by $0.15-0.25 \AA$. The comparison is complicated by the $\mathrm{pH}$ difference, 8.3 
vs. 6.0 for diffraction and spectroscopy, respectively. While the crystal structures indicate a significant increase (up to $0.25 \AA$ ) in the V-ligand distances for the peroxo form, the EXAFS shows a small (up to $0.10 \AA$ ) decrease, if a change at all, which is in line with the $C$. inaequalis VCPO XANES results [141].

\subsubsection{Outlook: merging XANES and EXAFS}

As mentioned in the introduction, the XANES region of the X-ray absorption spectrum is usually treated as spectroscopy (interpretation in terms of transitions) and the EXAFS as (X-ray induced electron) diffraction. The EXAFS is simulated with 1-dimensional structural models (radial distribution function independent of the arrangement of the atoms in space) or sometimes 2-dimensional (multiple scattering within an imidazole ring) or 3dimensional models (through-absorber multiple scattering involving linear arrangements of absorber and 2 ligand atoms). It has been recognized for some time that it should be possible to simulate the XANES on the basis of the same structural models, but defined in 3 dimensions, that account for the EXAFS; there is, however, as yet no convenient approach for the simulation of both regions of the spectra. The examples given above $[42,141]$ show that it is possible to simulate EXAFS data on the basis of the so-called 'muffin-tin potential' calculations, in which the atoms involved are potential wells separated by an area defined by a common interstitial potential. There is however a growing insight $[142,143]$ that such an approach is too crude to reproduce important features in the XANES, and that the more complex full-potential finite difference method [144] has to be applied to this region. The challenge now is to interpret both ranges of the spectrum with the same underlying theoretical model. One could go back and forth with one or more structural models between simulations of the XANES and EXAFS regions of the spectra, adjusting distance information in the EXAFS and 3-dimensional information in the XANES, until a consistent structural model has been reached. In view of the still increasing power of computational approaches such as the ADF Density Functional Theory package [145], it is also tempting to generate computational structures which can be validated/adjusted in both the EXAFS and XANES part of the X-ray absorption spectrum.

\section{Conclusions and future prospects}


During the last thirty years, extensive research on different vanadium-dependent haloperoxidases was undertaken in order to characterize halogenation through VHPOs. Based on information coming from crystal structures, model compounds of the cofactor possessing catalytic center have been analyzed and modeled in order to understand the vanadium coordination occurring in proteins [146], although these models only account for the first coordination sphere observed in proteins. Extensive modeling and chemical analyses have also helped advance on the understanding of the mechanistic reactivity of this metal-organic active center, by predicting the most stable functional model, $\mathrm{K}\left[\mathrm{VO}\left(\mathrm{O}_{2}\right)\right.$ (heida)], to be an effective biomimetic catalyst for VHPOs, also providing an explanation for the differences in chloro- and bromo-peroxidases [147]. Much progress has also been obtained by classical biochemical studies, X-ray crystallography and spectroscopic analyses of the global and fine local structures of the native and peroxo-intermediate forms of the enzymes. The resolution of a protein crystal-structure of a VHPO specific for iodide oxidation [56] has recently allowed further exploring the molecular origin of halide selectivity, which still remains an intriguing question. Indeed the halide specificity in VHPO is related to many interacting factors, such as the amino acid composition of the active site and the fine electronic environment of the vanadate pocket. This latter study also showed that the $2^{\text {nd }}$ coordination sphere of the peroxo intermediate appears to play an equally important role. In order to decipher the complete catalytic mechanisms of VHPOs and their contrasting reactivity towards different halides, it is important to pursue and enhance the combination of approaches, undertaking protein crystallographic studies in parallel to fine local structure analyses by XAS and EXAFS, on the different VHPO available and specific site-directed mutants that show modified biochemical kinetics. For instance, the fine tuning of the $\mathrm{VO}_{4}$ moiety during the catalytic cycle should be explored through the measurement and interpretation of the EXAFS and XANES of haloperoxidases at various edges in parallel (V, I, Br). These local structural studies not only provide a good starting point for computational studies on the protonation state of vanadate or on the catalytic intermediates [146, 148-151], but also provide the possibility to test structural hypotheses through analyses of point-mutants. VHPOs are indeed interesting models of research in chemistry to mimic the activity of vanadate centers, using oxidovanadium (IV) and dioxidovanadium (V) stabilized by organic molecules [45, 152]. However, recent studies [56] have shown that the influence of the protein stabilization of the active center goes beyond the first coordination sphere. At the long term, the biochemical and structural characterizations of known and supplementary VHPOs will be necessary, in particular at very high resolution (beyond $1 \AA$ ) and possibly using neutron-diffraction to precisely locate proton 
positions, to infer global evolution of VHPO enzymatic mechanisms among bacterial and eukaryotic lineages.

Another black box remains the biological roles of these enzymes in living organisms. The very large panel of halogenated compounds produced by marine organisms, especially by red and brown algae, is likely to have important biological or ecological functions. Moreover the presence of a tremendous number of VHPO-homologs in all bacterial lineages suggest the involvement of VHPO-based halogenation in numerous bacterial biosynthetic pathways. In this biological context, an important bottleneck is the development of functional approaches for deciphering the biochemical functions of VHPO, for finding their specific substrates and for identifying the natural halogenated products, they are producing in vivo. The set-up of heterologous expression and in vitro reconstituted systems are challenging, especially for marine bacteria, but the recent results obtained on Streptomyces sp. [69, 70] have opened interesting perspectives in this research area. In future developments, these advances will certainly give rise to potential biotechnological applications either for generating halogenated biologically active analogues or for improving biological properties of metabolites by enzymatic halogenation.

\section{Acknowledgements}

This work was supported by the 'Centre National de la Recherche Scientifique' and 'Université Pierre et Marie Curie, Paris 06', and by the French National Research Agency with regards to the investment expenditure program IDEALG (http://www.idealg.ueb.eu/, grant agreement No. ANR-10-BTBR-04). J.-B. Fournier was financially supported by Region Bretagne and CEA (ARED/TOXNUC-E program). We are very much grateful for assistance and technical help during XAS and EXAFS data collections as well as for very constructive and inspiring discussions during data collections to Stephanie Belin on beamline SAMBA (SOLEIL, Saint-Aubin, France), to Wim Bras and Dipanjan Banerjee on the dutch-belgian beamline DUBBLE from the European Synchrotron Radiation Facilities (ESRF, Grenoble, France), and to Wolfram Meyer-Klaucke from the EMBL Outstation at DESY (Hamburg, Germany). We are indebted to all local contacts for their precious support during crystal data collection at beamlines Proxima 1 (SOLEIL, Saint Aubin, France) and ID23 (ESRF, Grenoble, France). 


\section{REFERENCES}

[1] A. Butler, M. Sandy, Nature, 460 (2009) 848-854.

[2] G.W. Gribble, Chemosphere, 52 (2003) 289-297.

[3] G.W. Gribble, Occurrence of halogenated alkaloids., in: H.-J. Knölker (Ed.) The Alkaloids. Chemistry and Biology, Elsevier, 2012, pp. 1-142.

[4] S. Amachi, Microb. Env., 23 (2008) 269-276.

[5] S. La Barre, P. Potin, C. Leblanc, L. Delage, Mar. Drugs, 8 (2010) 988-1010.

[6] C. Paul, G. Pohnert, Nat. Prod. Rep., 28 (2011) 186.

[7] J.M. Winter, B.S. Moore, J. Biol. Chem., 284 (2009) 18577-18581.

[8] L.C. Blasiak, C.L. Drennan, Accounts Chem. Res., 42 (2009) 147-155.

[9] C. Wagner, M. El Omari, G.M. König, J. Nat. Prod., 72 (2009) 540-553.

[10] R. Wever, W. Hemrika, Vanadium haloperoxidases, in: J.W. Sons (Ed.) Handbook of Metalloproteins, 2006, pp. 1-12.

[11] J. A. Littlechild, Curr. Opin. Chem. Biol., 3 (1999) 28-34.

[12] L.P. Hager, D.R. Morris, F.S. Brown, H. Eberwein, J. Biol. Chem., 241 (1966) 17691777.

[13] C. Leblanc, C. Colin, A. Cosse, L. Delage, S. La Barre, P. Morin, B. Fiévet, C. Voiseux, Y. Ambroise, E. Verhaeghe, D. Amouroux , O. Donard, E. Tessier, P. Potin, Biochimie, 88 (2006) 1773-1785.

[14] F.C. Küpper, L.J. Carpenter, G.B. McFiggans, C.J. Palmer, T.J. Waite, E.-M. Boneberg, S. Woitsch, M. Weiller, R. Abela, D. Grolimund, P. Potin, A. Butler, G.W. Luther, P.M.H. Kroneck, W. Meyer-Klauckel, M.C. Feiters, Proc Nat Acad Sci USA, 105 (2008) 6954-6958. [15] H. Vilter, Phytochemistry, 23 (1984) 1387-1390.

[16] K.W. Glombitza, H.U. Rösener, H. Vilter, W. Rauwald, Planta Med., 24 (1973) 301-303.

[17] K.W. Glombitza, H.U. Rösener, Phytochem., 13 (1974) 1245-1247.

[18] K.-W. Glombitza, E. Sattler, Tetrahedron Lett., 14 (1973) 4277-4280.

[19] M. Ragan, K.-W. Glombitza, Phlorotannins, brown alga polyphenols., in: F.E. Round, D.J. Chapman (Eds.) Progress in Phycological Research, Biopress Ltd, Bristol, 1986, pp. 129252.

[20] H. Vilter, Methods Enzymol., 228 (1994) 665-672.

[21] H. Vilter, Vanadium-dependent haloperoxidases, in: H. Sigel, A. Sigel (Eds.) Metal ions in biological systems, Marcel Dekker, Inc., New York, Basel, Hong Kong, 1995, pp. 325-362. [22] M. Gajhede, Horseradish Peroxidase, in: John Wiley \& Sons (Ed.) Handbook in Metalloproteins, 2006, pp. 1-16. 
[23] M. Henze, Zeitschrift für Physiologische Chemie, 72 (1911).

[24] R.C. Burns, W.H. Fuchsman, R.W.F. Hardy, Biochem Biophys Res Commun, 42 (1971) 353.

[25] C.E. McKenna, J.R. Bennemann, T.G. Taylor, Biochem Biophys Res Commun, 41 (1970) 1501.

[26] E. de Boer, Y. van Kooyk, M.G.M. Tromp, H. Plat, R. Wever, Biochim. Biophys. Acta, 869 (1986) 48-53.

[27] R.L. Robson, R.R. Eady, T.H. Richardson, R.W. Miller, M. Hawkins, J.R. Postgate, Nature, 322 (1986) 388-390.

[28] L.L. Hopkins, in: W.G. Hoekstra (Ed.) Proceedings of the 2nd International Symposium in Trace Element Metabolism in Animals, University Park Press, Baltimore, 1974, pp. 397406.

[29] H.U. Meisch, J. Bauer, Arch Microbiol, 117 (1978) 49.

[30] H.U. Meisch, H. Brenzschawel, Arch Microbiol, 116 (1978) 91.

[31] H.U. Meisch, H. Brenzschawel, H.J. Blehg, Arch Microbiol, 114 (1977) 67.

[32] H.U. Meisch, H.J. Blehg, Arch Microbiol, 105 (1975) 77.

[33] L. Fries, Planta, 154 (1982) 393.

[34] E. de Boer, K. Boon, R. Wever, Biochemistry, 27 (1988) 1629-1635.

[35] E. de Boer, M.G.M. Tromp, H. Plat, B.E. Krenn, R. Wever, Biochim. Biophys. Acta, 872 (1986) 104-115.

[36] Knüttel, Müller, Rehder, Vilter, Wittneben, FEBS Lett., 302 (1992) 11-14.

[37] H. Vilter, D. Rehder, Inorg Chim Acta, 136 (1987) L7-L10.

[38] D. Rehder, Holst, Priebsch, H. Vilter, J Inorg Biochem, 41 (1991) 171-185.

[39] M. Weyand, H.J. Hecht, M. Kiess, M.-F. Liaud, H. Vilter, D. Schomburg, J. Mol. Biol., 293 (1999) 595-611.

[40] A. Müller-Fahrnow, W. Hinrichs, W. Saenger, H. Vilter, FEBS Lett., 239 (1988) 292294.

[41] J. Hormes, U. Kuetgens, R. Chauvistre, W. Schreiber, N. Anders, H. Vilter, D. Rehder, C. Weidemann, Biochim. Biophys. Acta, 956 (1988) 293-299.

[42] J.M. Arber, E. de Boer, C.D. Garner, S.S. Hasnain, R. Wever, Biochemistry, 28 (1989) 7968-7973.

[43] U. Küsthardt, B. Hedman, K.O. Hodgson, R. Hahn, H. Vilter, FEBS Lett., 329 (1993) 58.

[44] D. Wischang, O. Brücher, J. Hartung, Coord. Chem. Rev., 255 (2011) 2204- 2217. 
[45] E. de Boer, H. Plat, M.G.M. Tromp, R. Wever, M.C.R. Franssen, H.C. van der Plas, E.M. Meijer, H.E. Schoemaker, Biotechnol. Bioeng., 30 (1987) 607.

[46] H.S. Soedjak, A. Butler, Inorg. Chem., 29 (1990) 5015-5017.

[47] P. Jordan, H. Vilter, Biochim. Biophys. Acta, 1073 (1991) 98-106.

[48] E. de Boer, R. Wever, J. Biol. Chem., 263 (1988) 12326-12332.

[49] R.R. Everett, J.R. Kanofsky, A. Butler J. Biol. Chem., 265 (1990) 4908-4914.

[50] R.R. Everett, H.S. Soedjak, A. Butler, J. Biol. Chem., 265 (1990) 15671-15679.

[51] M. Almeida, S. Filipe, M. Humanes, M.F. Maia, R. Melo, N. Severino, J.A.L. da Silva, J.J.R. Frausto da Silva, R. Wever, Phytochem., 57 (2001) 633-642.

[52] M. Almeida, M. Humanes, J.A. Silva, R. Melo, J.J.R. Frausto da Silva, Phyllariopsis brevipes- a brown algae with vanadium-dependent iodoperoxidases, in: C. Obinger, U. Burner, R. Ebermann, C. Penel, H. Greppin (Eds.) Plant Peroxidases: Biochemistry and Physiology, University of Geneve, Geneve, 1996, pp. 146-152.

[53] C. Colin, C. Leblanc, E. Wagner, L. Delage, E. Leize-Wagner, A. van Dorsselaer, B. Kloareg, P. Potin, J. Biol. Chem., 278 (2003) 23545-23552.

[54] C. Colin, C. Leblanc, G. Michel, E. Wagner, E. Leize-Wagner, A. van Dorsselaer, P. Potin, J. Biol. Inorg. Chem., 10 (2005) 156-166.

[55] E. Verhaeghe, D. Buisson, E. Zekri, C. Leblanc, P. Potin, Y. Ambroise, Anal. Biochem., 379 (2008) 60-65.

[56] J.-B. Fournier, E. Rebuffet, L. Delage, R. Grijol, L. Meslet-Cladière, J. Rzonca, P. Potin, G. Michel, M. Czjzek, C. Leblanc, Appl. Environ. Microbiol., 80 (2014) 7561-7573.

[57] R. Wever, H. Plat, E. de Boer, Biochim. Biophys. Acta, 830 (1985) 181-186.

[58] W. Hemrika, R. Renirie, S. Macedo-Ribeiro, A. Messerschmidt, R. Wever, J. Biol. Chem., 274 (1999) 23820-23827.

[59] T. Ohshiro, W. Hemrika, T. Aibara, R. Wever, Y. Izumi, Phytochem., 60 (2002) 595601.

[60] D. Wischang, M. Radlow, H. Schulz, H. Vilter, L. Viehweger, M.O. Altmeyer, C.

Kegler, J. Herrmann, R. Müller, F. Gaillard, L. Delage, C. Leblanc, J. Hartung, Bioorg. Chem., 44 (2012) 25-34.

[61] M.G.M. Tromp, G. Olafsson, B.E. Krenn, R. Wever, Biochim. Biophys. Acta, 1040 (1990) 192-198.

[62] J.W. van Schijndel, E.G.M. Vollenbroek, R. Wever, Biochim. Biophys. Acta, 1161 (1993) 249-256.

[63] M.G.M. Tromp, T.T. Van, R. Wever, Biochim. Biophys. Acta, 1079 (1991) 53-56. 
[64] D.R. Smith, S. Grüschow, R.J. Goss, Curr. Op. Chem. Biol., 17 (2013) 276-283.

[65] E. Coupe, M. Smyth, A. Fosberry, R. Hall, J. Littlechild, Protein Expr Purif., 52 (2007) 265-272.

[66] Z. Hasan, R. Renirie, R. Kerkman, H.J. Ruijssenaars, A.F. Hartog, R. Wever, J. Biol. Chem., 281 (2006) 9738-9744.

[67] M. Shimonishi, S. Kuwamoto, H. Inoue, R. Wever, T. Ohshiro, Y. Izumi, T. Tanabe, FEBS lett., 428 (1998) 105-110.

[68] P. Bernhardt, T. Okino, J.M. Winter, A. Miyanaga, B.S. Moore, J. Am. Chem. Soc., 133 (2011) 4268-4270.

[69] L. Kaysser, P. Bernhardt, S.-J. Nam, S. Loesgen, J.G. Ruby, P. Skewes-Cox, P.R. Jensen, W. Fenical, B.S. Moore, J. Am. Chem. Soc., 134 (2012) 11988-11991.

[70] R. Teufel, L. Kaysser, M.T. Villaume, S. Diethelm, M.K. Carbullido, P.S. Baran, B.S. Moore, Angew. Chem. Int. Ed., 53 (2014) 11019 -11022.

[71] B.E. Krenn, M.G.M. Tromp, R. Wever, J. Biol. Chem., 32 (1989) 19287-19292.

[72] D. Wischang, J. Hartung, Tetrahedron, 67 (2011) 4048-4054.

[73] D. Wischang, J. Hartung, Tetrahedron, 68 (2012) 9456-9463.

[74] F.C. Küpper, N. Schweigert, E. Ar Gall, J.-M. Legendre, H. Vilter, B. Kloareg, Planta, 207 (1998) 163-171.

[75] E.F. Verhaeghe, A. Fraysse, J.-L. Guerquin-Kern, T.-D. Wu, G. Devès, C. Mioskowski, C. Leblanc, R. Ortega, Y. Ambroise, P. Potin, J Biol Inorg Chem, 13 (2008) 257-269.

[76] H. Yamada, N. Itoh, S. Murakami, Y. Izumi, Agric. Biol. Chem., 49 (1985) 2961-2967.

[77] N. Itoh, Y. Izumi, H. Yamada, Biochem. Biophys. Res. Commun., 131 (1985) 428-435.

[78] N. Itoh, Y. Izumi, H. Yamada, J. Biol. Chem., 261 (1986) 5194-5200.

[79] B.E. Krenn, Y. Izumi, H. Yamada, R. Wever, Biochim. Biophys. Acta, 998 (1989) 63-68.

[80] M. Sandy, J.N. Carter-Franklin, J.D. Martiny, A. Butler, Chem. Commun., 47 (2011) 12086-12088.

[81] H. Baharum, W.C. Chu, S.S. Teo, K.Y. Ng, R.A. Rahim, C.L. Ho, Phytochem., 92 (2013) 49-59.

[82] J.N. Carter-Franklin, A. Butler, J. Am. Chem. Soc., 126 (2004) 15060-15066.

[83] S.A. Borchardt, E.J. Allain, J.J. Michels, G.W. Stearns, R.F. Kelly, W.F. McCoy, Appl. Env. Microb., 67 (2001) 3174-3179.

[84] S. Salaün, S. La Barre, M. Dos Santos-Goncalvez, P. Potin, D. Haras, A. Bazire, Microb. Ecol., 64 (2012) 359-369. 
[85] B.H. Simons, P. Barnett, E.G.M. Vollenbroek, H.L. Dekker, A.O. Muijsers, A.

Messerschmidt, R. Wever, Eur. J. Biochem., 229 (1995) 566-574.

[86] P. Ortiz-Bermúdez, K.C. Hirth, E. Srebotnik, K.E. Hammel, Proc Nat Acad Sci USA, 104 (2007) 3895-3900.

[87] I.F. Persoon, M.A. Hoogenkamp, A. Bury, P.R. Wesselink, A.F. Hartog, R. Wever, W. Crielaard, J. Endodont., 38 (2012) 72-74.

[88] J.M. Winter, M.C. Moffitt, E. Zazopoulos, J.B. McAlpine, P.C. Dorrestein, B.S. Moore, J Biol Chem., 282 (2007) 16362-16368.

[89] K.-H. van Pée, F. Lingens, J. Gen. Microbiol., 131 (1985) 1911-1916.

[90] P. Barnett, W. Hemrika, H.L. Dekker, A.O. Muijsers, R. Renirie, R. Wever, J. Biol. Chem., 273 (1998) 23381-23387.

[91] T.L. Johnson, B. Palenik, B. Brahamsha, J. Phycol., 47 (2011) 792-801.

[92] A. Messerschmidt, R. Wever, Proc. Nat. Acad. Sci. U.S.A., 93 (1996) 392-396.

[93] M.N. Isupov, A.R. Dalby, A.A. Brindley, Y. Izumi, T. Tanabe, G.N. Murshudov, J.A.

Littlechild, J. Mol. Biol., 299 (2000) 1035-1049.

[94] J.A. Littlechild, E. Garcia-Rodriguez, Coord. Chem. Rev., 237 (2003) 65-76.

[95] N. Marianayagam, M. Sunde, J. Matthews, Trends Biochem Sci., 29 (2004) 618-625.

[96] J.A. Littlechild, E. Garcia-Rodriguez, A.R. Dalby, M.N. Isupov, J. Mol. Recogn., 15 (2002) 291-296.

[97] J. Littlechild, E.G. Rodriguez, M.N. Isupov, J. Inorg. Biochem., 103 (2009) 617-621.

[98] K. Ishikawa, Y. Mihara, K. Gondoh, E. Suzuki, Y. Asano, EMBO J., 19 (2000) $2412-$ 2423.

[99] W. Hemrika, R. Renirie, H.L. Dekker, P. Barnett, R. Wever, Proc. Nat. Acad. Sci. U.S.A, 94 (1997) 2145-2149.

[100] A.F. Neuwald, Protein Sci., 6 (1997) 1764-1767.

[101] S. Macedo-Ribeiro, R. Renirie, R. Wever, A. Messerschmidt, Biochem., 47 (2008) 929934.

[102] J. Singh, R.C. Nordlie, R.A. Jorgenson, Biochim. Biophys. Acta, 678 (1981) 477-482.

[103] E. Garcia-Rodriguez, T. Ohshiro, T. Aibara, Y. Izumi, J. Littlechild, J. Biol. Inorg. Chem., 10 (2005) 275-282.

[104] S.R. Akabayov, B. Akabayov, Inorg. Chim. Acta, 420 (2014) 16-23.

[105] A. Messerschmidt, L. Prade, R. Wever, Biol. Chem., 378 (1997) 309-315.

[106] S. Macedo-Ribeiro, W. Hemrika, R. Renirie, R. Wever, A. Messerschmidt, J. Biol. Inorg. Chem., 4 (1999) 209-219. 
[107] T. Ohshiro, J.A. Littlechild, E. Garcia-Rodriguez, M.N. Isupov, Y. Iida, T. Kobayashi, Y. Izumi, Protein Sci., 13 (2004) 1566-1571.

[108] R.W. Strange, M.C. Feiters, Curr. Opin. Struct. Biol., 18 (2008) 1-8.

[109] M.C. Feiters, W. Meyer-Klaucke, in: R.R. Crichton, R. Louro (Eds.) Practical Approaches to Biological Inorganic Chemistry, Elsevier, 2013, pp. 131-160.

[110] F.C. Küpper, L.J. Carpenter, C. Leblanc, C. Toyama, Y. Uchida, B. Maskrey, J.

Robinson, E.F. Verhaeghe, G. Malin, G.W.L. III, P.M.H. Kroneck, B. Kloareg, W. Meyer-

Klaucke, Y. Muramatsu, I.L. Megson, P. Potin, M.C. Feiters, J. Exp. Bot., 64 (2013) 26532664.

[111] F.C. Küpper, C. Leblanc, W. Meyer-Klaucke, P. Potin, M.C. Feiters, J. Phycol., 50 (2014) 652-664.

[112] M.C. Feiters, C. Leblanc, F.C. Küpper, W. Meyer-Klaucke, G. Michel, P. Potin, J. Am. Chem. Soc., 127 (2005) 15340-15341.

[113] T.D. Tullius, W.O. Gillum, R.M.K. Carlson, K.O. Hodgson, J. Am. Chem. Soc., 102 (1980) $5670-5676$.

[114] D.E. Ryan, K.B. Grant, K. Nakanish, P. Frank, K.O. Hodgson, Biochem., 35 (1996) 8651-8661.

[115] P. Frank, K.O. Hodgson, K. Kustin, W.E. Robinson, J. Biol. Chem., 273 (1998) 2449824503.

[116] P. Frank, K.O. Hodgson, Inorg. Chem., 39 (2000) 6018-6027.

[117] P. Frank, R.M.K. Carlson, E.J. Carlson, K.O. Hodgson, Coord. Chem. Rev., 237 (2003) 31-39.

[118] P. Frank, R.M.K. Carlson, E.J. Carlson, K.O. Hodgson, J. Inorg. Biochem., 94 (2003) $59-71$.

[119] P. Frank, E.J. Carlson, R.M.K. Carlson, B. Hedman, K.O. Hodgson, J Inorg Biochem, 102 (2008) 809-823.

[120] P. Frank, B. Hedman, R.M.K. Carlson, K.O. Hodgson, Inorg. Chem., 33 (1994) 37943803.

[121] P. Frank, B. Hedman, K.O. Hodgson, Inorg, Chem., 38 (1999) 260-270.

[122] P. Frank, B. Hedman, K.O. Hodgson, J Inorg. Biochem., 131 (2004) 99-108.

[123] K. Takemoto, T. Ueki, B. Fayard, A. Yamamoto, M. Salomé, S. Scippa, I. Susini, T. Uyama, H. Michibata, H. Kihara, J. Phys. IV, 104 (2003) 333-336. 
[124] M.D. de Jonge, C. Holzner, S.B. Baines, B.S. Twining, K. Ignatyev, J. Diaz, D.L.

Howard, D. Legninie, A. Micelie, I. McNultye, C.J. Jacobsen, S. Vogt, Proc. Natl. Acad. Sci. U.S.A., 107 (2010) 15676-15680.

[125] K. Takemoto, T. Ueki, B. Fayard, A. Yamamoto, M. Salomé, S. Scippa, I. Susini, T. Uyama, H. Michibata, H. Kihara, J. Phys. IV, 104 (2003) 333-336.

[126] K. Takemoto, T. Ueki, B. Fayard, M. Salomé, J. Susini, A. Yamamoto, S. H, S. Scippa, H. Michibata, H. Kihara, Proc. 8th Int. Conf. X-ray Microscopy, IPAP Conf., Series 7 (2006) 213-216.

[127] P.E. Bishop, D.M.L. Jarlenski, D.R. Hetherington, J. Bacteriol., 150 (1988) 1244-1251. [128] J.M. Arber, B.M. Dobson, R.E. Eady, P. Stevens, S.S. Hasnain, C.D. Garner, B.E. Smith, Nature, 325 (1987) 372-374.

[129] J. Wong, F.W. Lytle, R.P. Messmer, D.H. Maylotte, Phys. Rev. B., 30 (1984) 55965610 .

[131] I. Sagi, Y. Hochman, G. Bunker, S. Carmeli, C. Carmeli, Photosynthesis Res., 57 (1998) 275-285.

[131] C.J. Carrano, M. Mohan, S.M. Holmes, R.d.l. Rosa, A. Butler, J.M. Charnock, C.D. Garner, Inorg. Chem., 33 (1994) 646-655.

[132] H.H. Thorp, Inorg. Chem., 31 (1992) 1585-1588.

[133] E. de Boer, C.P. Keijzers, A.A.K. Klaassen, E.J. Reijerse, D. Collison, C.D. Garner, R. Wever, FEBS Lett., 235 (1988) 93-97.

[134] L.J. Calviou, J.M. Arber, D. Collison, C.D. Garner, W. Clegg, J. Chem. Soc. Chem. Commun., (1992) 654-656.

[135] M.C. Feiters, W. Meyer-Klaucke, A. Kostenko, A. Soldatov, C. Leblanc, G. Michel, P. Potin, F.C. Küpper, K. Hollenstein, K. Locher, L. Bevers, P. Hagedoorn, W. Hagen, J. Phys.: Conf. Series, 190 (2009) 012196.

[136] K. Hollenstein, M. Comellas-Bigler, L.E. Bevers, M.C. Feiters, W. Meyer-Klaucke, P.L. Hagedoorn, K.P. Locher, J. Biol. Inorg. Chem., 14 (2009) 663-672.

[137] M.C. Feiters, C. Leblanc, G. Michel, P. Potin, F.C. Küpper, W.Meyer-Klaucke, A.V.

Kostenko, A.V. Soldatov, in: B.L. M. Texeira, M. De la Rosa (Ed.) EUROBIC-8,

Normagrafe, Lda.-Santarem, Aveiro, Portugal, 2006.

[138] U. Christmann, H. Dau, M. Haumann, E. Kiss, P. Liebisch, D. Rehder, G. Santoni, C.

Schulzke, Dalton Trans., (2004) 2534-2540.

[139] D. Rehder, C. Schulzke, H. Dau, C. Meinke, J. Hanss, M. Epple, J. Inorg. Biochem., 80 (2000) 115-121. 
[140] H. Dau, J. Dittmer, M. Epple, J. Hanss, E. Kiss, D. Rehder, C. Schulzke, H. Vilter, FEBS Letters, 457 (1999) 237-240.

[141] R. Renirie, J.M. Charnock, C.D. Garner, R. Wever, J. Inorg. Biochem., 104 (2010) 657664.

[142] A.V. Kostenko, M.C. Feiters, A.N. Kravtsova, A.V. Soldatov, J. Surf. Investig.. X-ray, Synchrotron and Neutron Techniques, 2 (2009) 900-903.

[143] J.-B. Fournier, L. Delage, S. Belin, P. Potin, M. Feiters, M. Czjzek, P.-L. Solari, C.

Leblanc, Eur. Biophys. J. with Biophys. Lett., 42 (2013) S176.

[144] Y. Joly, Phys. Rev. B., B 63 (2001) 125120.

[145] G. te Velde, F.M. Bickelhaupt, E.J. Baerends, C. Fonseca Guerra, S.J.A. van Gisbergen, J.G. Snijders, T. Ziegler, J. Comp. Chem., 22 (2001) 931-967.

[146] D. Sanna, V.L. Pecoraro, G. Micera, E. Garribba, J Biol Inorg Chem, 17 (2012) 773 790.

[147] C.J. Schneider, G. Zampella, C. Greco, V.L. Pecoraro, L. De Gioia, Eur. J. Inorg. Chem., (2007) 515-523.

[148] G. Zampella, P. Fantucci, V.L. Pecoraro, L. De Gioia, J. Am. Chem. Soc., 127 (2005) 953-960.

[149] W. Plass, Pure Appl. Chem., 81 (2009) 1229-1239.

[150] J. Yudenfreund Kravitz, V. L. Pecoraro, H. A. Carlson, J. Chem. Theory Comput., 1 (2005) 1265-1274.

[151] Y. Zhang, J. Gascón, J. Inorg. Biochem., 102 (2008) 1684-1690.

[152] G. Licini, V. Conte, A. Coletti, M. Mba, C. Zonta, Coord. Chem. Rev., 255 (2011) $2345-2357$.

[153] J.N. Carter, K.E. Beatty, M.T. Simpson, A. Butler, J. Inorg. Biochem., 91 (2002) 59-69. [154] R. Renirie, W. Hemrika, R. Wever, J. Biol. Chem., 275 (2000) 11650-11657. 
Table 1. Biochemical, molecular and structural characterization of vanadium-dependent haloperoxidases.

\begin{tabular}{|c|c|c|c|c|c|c|}
\hline & Species & Activity & $\begin{array}{c}\text { GenBank } \\
\text { Accession \# }\end{array}$ & $\begin{array}{c}P D B \\
\text { Accession \# }\end{array}$ & Mutants & References \\
\hline \multirow{2}{*}{ 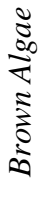 } & $\begin{array}{l}\text { Ascophyllum } \\
\text { nodosum }\end{array}$ & $\begin{array}{l}\text { VBPOI } \\
\text { VBPOII }\end{array}$ & $\begin{array}{c}\text { P81701 } \\
\text { CCD42013 }\end{array}$ & $\begin{array}{c}1 \mathrm{QI} 9^{\mathrm{b}} \\
-\end{array}$ & $\begin{array}{l}- \\
-\end{array}$ & $\begin{array}{l}{[15],[39]} \\
{[60]}\end{array}$ \\
\hline & Laminaria digitata & $\begin{array}{l}\text { VBPO } \\
\text { VIPO }\end{array}$ & $\begin{array}{l}\text { CAD37191 } \\
\text { CAF04025 }\end{array}$ & $\begin{array}{l}- \\
-\end{array}$ & - & $\begin{array}{l}{[53]} \\
{[54]}\end{array}$ \\
\hline \multirow{4}{*}{ 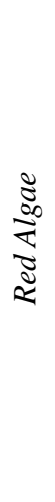 } & Corallina officinalis & VBPO & $\begin{array}{l}\text { AF218810 } \\
\text { AAM46061 }\end{array}$ & $\begin{array}{c}1 \mathrm{QHB}^{\mathrm{b}} \\
-\end{array}$ & $\begin{array}{c}- \\
\mathrm{H} 480 \mathrm{~A}\end{array}$ & $\begin{array}{l}{[93]} \\
{[65,153]}\end{array}$ \\
\hline & Corallina pilulifera & $\begin{array}{l}\text { VBPOI } \\
\text { VBPOII }\end{array}$ & $\begin{array}{l}\text { 1UP8_A }{ }^{\mathrm{a}} \\
\text { BAA31261 } \\
\text { BAA31262 }\end{array}$ & $\begin{array}{c}1 \mathrm{UP} 8 \\
-\end{array}$ & R397X & {$[67,94,103,107]$} \\
\hline & Gracilaria changii & VBPO & AGE00855 & & $\mathrm{R} 379 \mathrm{~F} / \mathrm{H}$ & {$[81]$} \\
\hline & Delisea pulchra & VBPO & $\begin{array}{l}\text { DpDV-BrPO } \\
\text { DpEV-BrPO }\end{array}$ & - & $\mathrm{R} 553 \mathrm{H}$ & {$[80]$} \\
\hline \multirow[t]{2}{*}{ 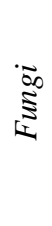 } & Curvularia inaequalis & $\mathrm{VCPO}$ & CAA59686 & $\begin{array}{l}1 \mathrm{VNC}^{\mathrm{b}}, 1 \mathrm{IDQ}, \\
1 \mathrm{IDU}, 1 \mathrm{VNE}-\mathrm{I}, \\
1 \mathrm{VNS}, 3 \mathrm{BB} 0\end{array}$ & $\begin{array}{c}\text { D292A, K353A, R360A, } \\
\text { F397H, S402A, H404A, } \\
\text { R490A, H496A, } \\
\text { P395D/L241V/T343A }\end{array}$ & $\begin{array}{l}{[58,66,85,92,} \\
101,105,106, \\
154]\end{array}$ \\
\hline & $\begin{array}{l}\text { Alternaria } \\
\text { didymospora }\end{array}$ & $\mathrm{VCPO}$ & CAA72622 & - & - & {$[80]$} \\
\hline \multirow{4}{*}{ 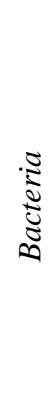 } & $\begin{array}{l}\text { Zobellia } \\
\text { galactanivorans }\end{array}$ & $\begin{array}{l}\text { VIPO1 } \\
\text { VIPO2 }\end{array}$ & $\begin{array}{l}\text { YP_004735706 } \\
\text { YP_004736527 }\end{array}$ & $4 \mathrm{CIT}$ & $\begin{array}{c}\text { Y263A/S/F, C320S, } \\
\text { W321A, D322K/Y, } \\
\text { F353H, S358A, H360A, } \\
\text { R410A }\end{array}$ & {$[56]$} \\
\hline & $\begin{array}{l}\text { Synechococcus sp. } \\
\text { WH } 8020\end{array}$ & VBPO & ADO20318 & - & 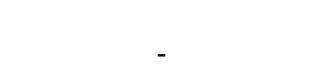 & [91] \\
\hline & $\begin{array}{l}\text { Streptomyces sp. } \\
\text { CNQ-525 }\end{array}$ & $\mathrm{VCPO}$ & ABS50486 & $3 \mathrm{~W} 36$ & $\mathrm{H} 420 \mathrm{~F}, \mathrm{~S} 427 \mathrm{H}$ & {$[68]$} \\
\hline & $\begin{array}{l}\text { Streptomyces sp. } \\
\text { CNH-189 }\end{array}$ & VCPO & $\begin{array}{l}\text { AGH68925 } \\
\text { AGH68909 }\end{array}$ & - & - & {$[69,70,88]$} \\
\hline
\end{tabular}

VBPO: vanadium-dependent bromoperoxidase; VIPO: vanadium-dependent iodoperoxidase; VCPO: vanadium-dependent chloroperoxidase; X: all amino acids except $\mathrm{R} ;{ }^{\mathrm{a}}$ obtained by protein sequencing; ${ }^{\mathrm{b}}$ resolution of the crystal structure from the purified native protein 


\section{Figure legends}

Scheme 1. Proposed mechanism for vanadium-dependent haloperoxidase, with $\mathrm{X}^{-}=$ halide. Left: ping-pong mechanism for the formation of the reactive intermediate $\mathrm{OX}^{-}$or ' $\mathrm{X}^{+}$'. Ellipsoids indicate the equatorial planes of the trigonal bipyramidal and square planar coordination geometries of the native (top) and peroxo (bottom) enzyme forms, respectively. $\mathrm{H}_{2} \mathrm{O}_{2}$ atoms are tracked in red bold in the peroxo enzyme form (notice that one of the $\mathrm{O}$ in the vanadate of the native enzyme also originates from $\mathrm{H}_{2} \mathrm{O}_{2}$ ). Right: Overall reactions of the VHPO/ $\mathrm{H}_{2} \mathrm{O}_{2}$ system. X: Br, Cl, I. R-H: organic compound. R-X: organohalogens.

\section{Figure 1. Phylogeny of VHPO proteins.}

A protein maximum likelihood (PML) tree was constructed using the multiple alignment of 26 eukaryote and bacterial VHPOs characterized at the molecular and/or biochemical levels and of four Bacterial Acid Phosphatases as an outgroup. 173 informative residues were used for PML analyses and bootstrap values (500 replicates) are provided for main nodes. The NCBI accession numbers of proteins are indicated, except for VBPO from Plocanium cartilagineum (Pcar) and from Delisea pulchra (Dpul) (see [80]). The scale bar represents a difference of 0.1 substitution per site. When characterized at the biochemical level, the VHPO specificity towards halides is mentioned and refers to the legend code, i.e. iodo- (VIPO), bromo- (VBPO) or chloroperoxidase (VCPO) activity. The available 3D structures of VHPO are indicated by a star. Examples of halogenated products are $\alpha-, \beta$ - and $\gamma$-snyderol and (+)$3 \beta$-bromo-8-epicaparrapi oxide [80], bromofuranone [80], napyradiomycin [68], merochlorin $[69,70]$, bromopyrroles [72] and bromophenols [73].

Figure 2. Three dimensional structures of VHPO. A. The monomeric VCPO from $C$. inaequalis (PDB Accession \#, 1VNI). B. The monomeric VIPO1 from Z. galactanivorans (PDB 4CIT). C. The homo-dimeric VBPOI from A. nodosum (PDB 1QI9). D. The dodecameric VBPO from Corallina officinalis (PDB 1QHB) and C. pilulifera (PDB 1UP8). In the monomeric VHPOs (A and B), the N- and C- terminal parts of the protein containing the two helix-bundle domains are colored in blue and red, respectively. For the algal VHPOs, the red and blue colors are used to distinguish either the two identical monomers (B) or the different homodimers (D). The $\mathrm{VO}_{4}$ binding sites are indicated by an arrow. 
Figure 3. 3D structure comparaison of VIPO1 from Z. galactanivorans (PDB Accession \#, 4CIT) and of non-specific acid phosphatase from Escherichia blattae (PBD 1D2T). A. Superimposition of the N-terminal helix bundle (in green) of Zg-VIPO1 onto its C-terminal helix bundle (in blue). B. Superimposition of the monomeric structure of Eb-NSAP (in pink) with a monomer of Zg-VIPO1 (in blue and green). The C-terminal helix-bundle that is conserved with other VHPO is represented in blue and the N-terminal helix bundle is colored in green. The $\mathrm{VO}_{4}$ or $\mathrm{PO}_{4}$ binding site is indicated by an arrow.

Figure 4. Comparison of vanadate-binding site structures of VHPO. A. VIPO1 from $Z$. galactanivorans (Zg-VIPO1, PDB Accession \#, 4CIT). B. VCPO from Curvularia inaequalis (Ci-VCPO, PDB 1IDQ). C. VCPO from Streptomyces sp. CNQ525 (Ssp-VCPO, PDB 3W36). D. VBPOI from A. nodosum (An-VBPOI, PDB 1QI9). E: VBPO from Corallina officinalis (Co-VBPO, PDB 1QHB). F. VBPO from Corallina pilulifera (Cp-VBPO, PDB 1UP8). The view of the active site is looking inside, towards the axial histidine ligand at the bottom of the $20 \AA$ deep cavity, and amino acid residues are numbered according to the protein sequence. Vanadate and phosphate are represented in the center of the picture. The H-bonds between $\mathrm{VO}_{4}$ or $\mathrm{PO}_{4}$ group and the surrounding amino acids are shown as dashed blue lines.

Figure 5. Example of vanadium K-edge X-ray absorption spectra. Comparison of (dashed red) $\mathrm{Na}_{3} \mathrm{VO}_{4}$ in Tris buffer $\mathrm{pH} 8.0$ and (solid black) native VBPOI from Ascophyllum nodosum. X-ray absorption near edge spectra (XANES, top left, A) and $1^{\text {st }}$ derivative (bottom left, B); extracted Extended X-ray Absorption Fine Structure (EXAFS, top right, C) and phase-corrected modulus of the Fourier transform of the EXAFS (bottom right, D). Spectra taken with Dr. W. Meyer-Klaucke at the EMBL Outstation at DESY, Hamburg, Germany. 


\section{Highlights}

- 3D and XAS data are complementary to study Vanadium coordination and VHPO catalysis.

- VHPO features a large evolutionary and structural diversity from bacteria to algae.

- Bacterial VHPO revealed new biosynthesis pathways and enzymatic specificity.

\section{Graphical abstract}

The 3D-printed protein structure ${ }^{(*)}$ and vanadium X-ray absorption near edge spectra obtained from the first vanadium haloperoxidase discovered 30 years ago.
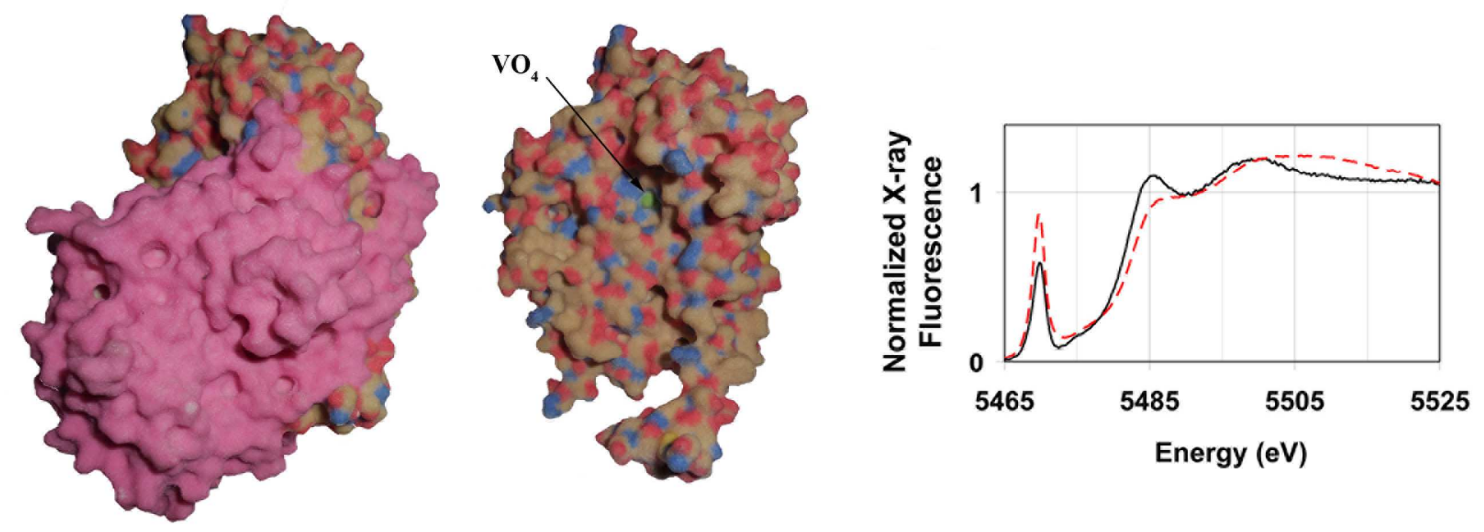

(*) http://vilter.de/vanadium-dependent-haloperoxidase-from-ascophyllum-nodosumtouchable-3d-models-from-X-ray-crystallography-to-3d-print/ 


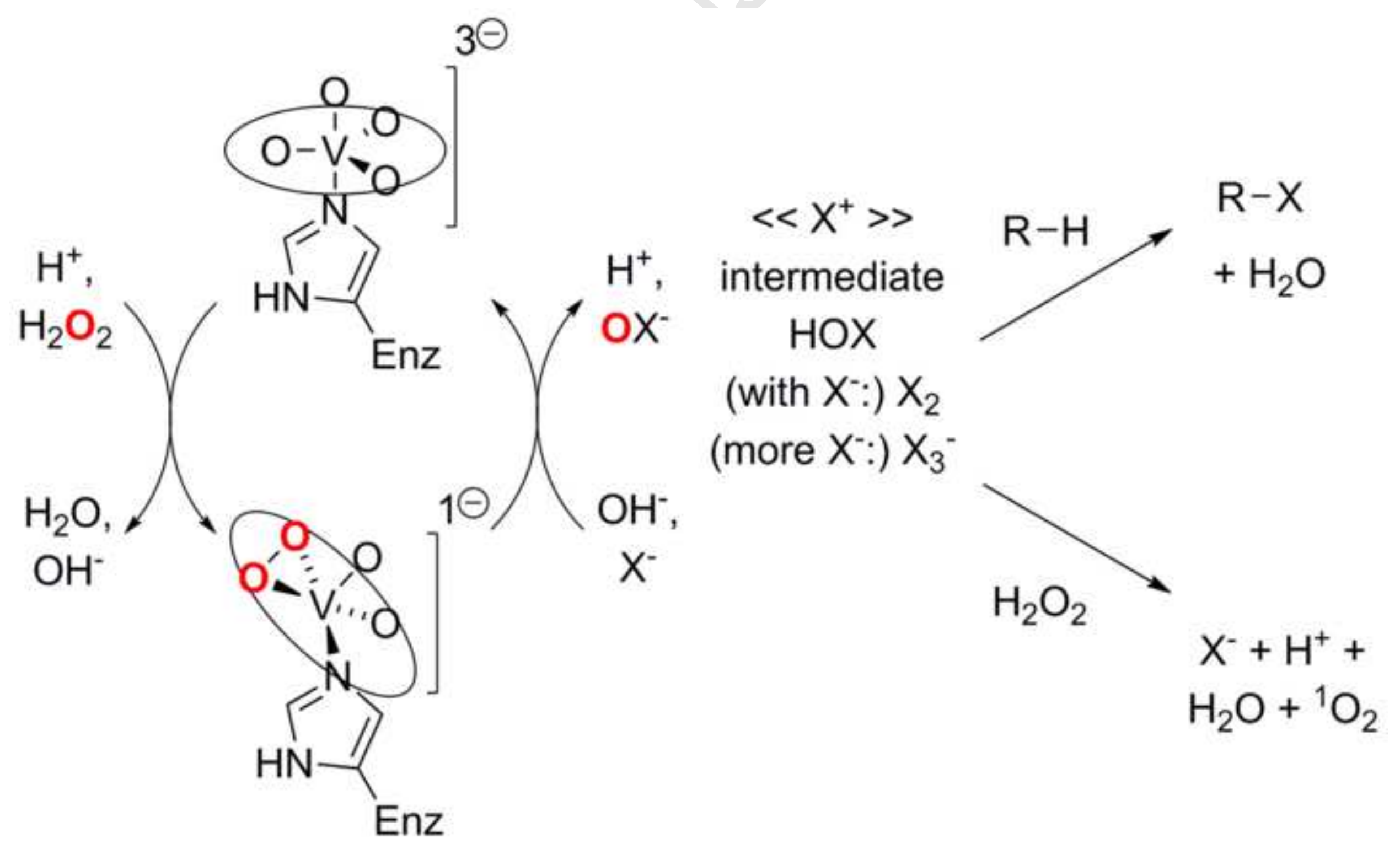




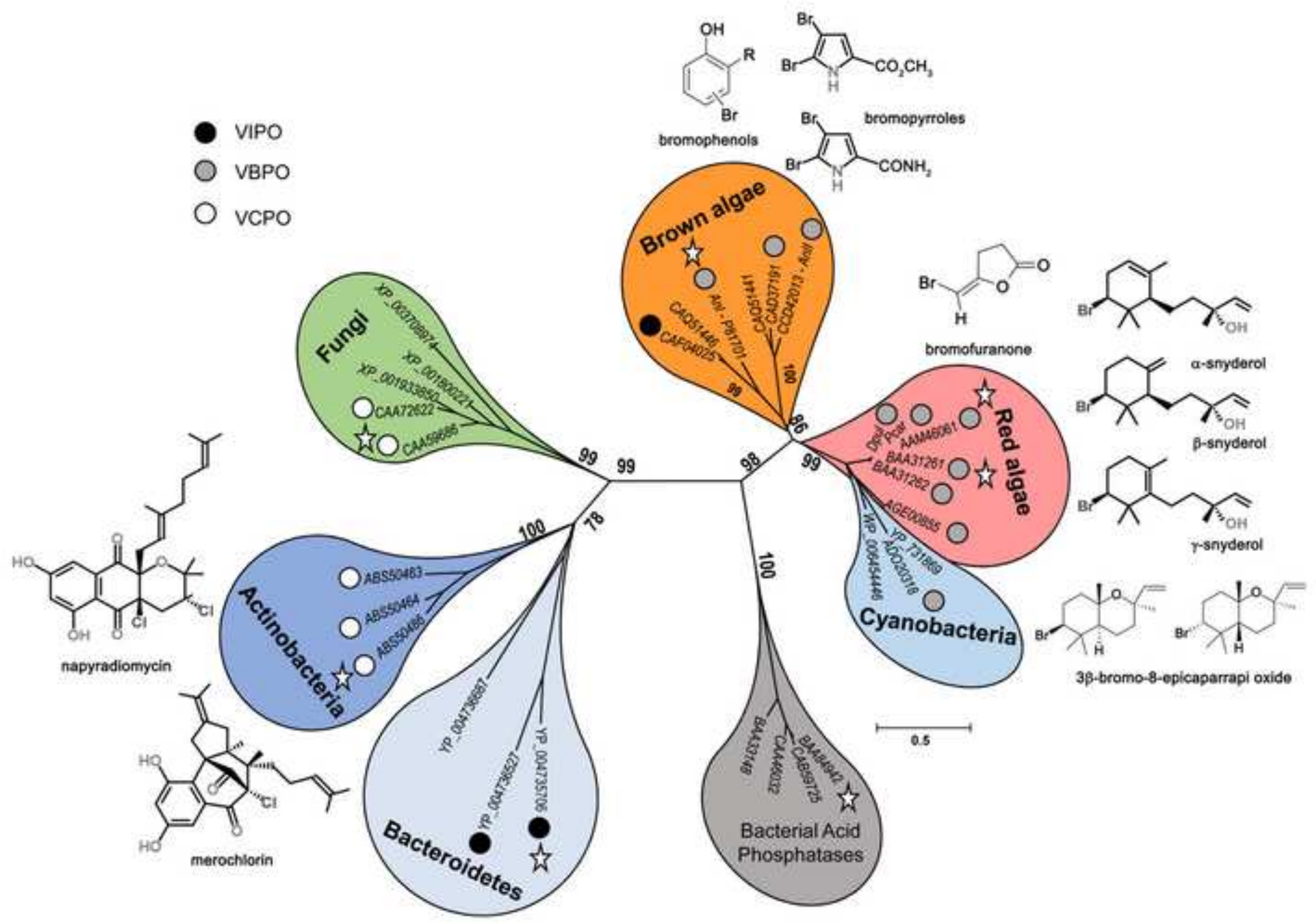


A

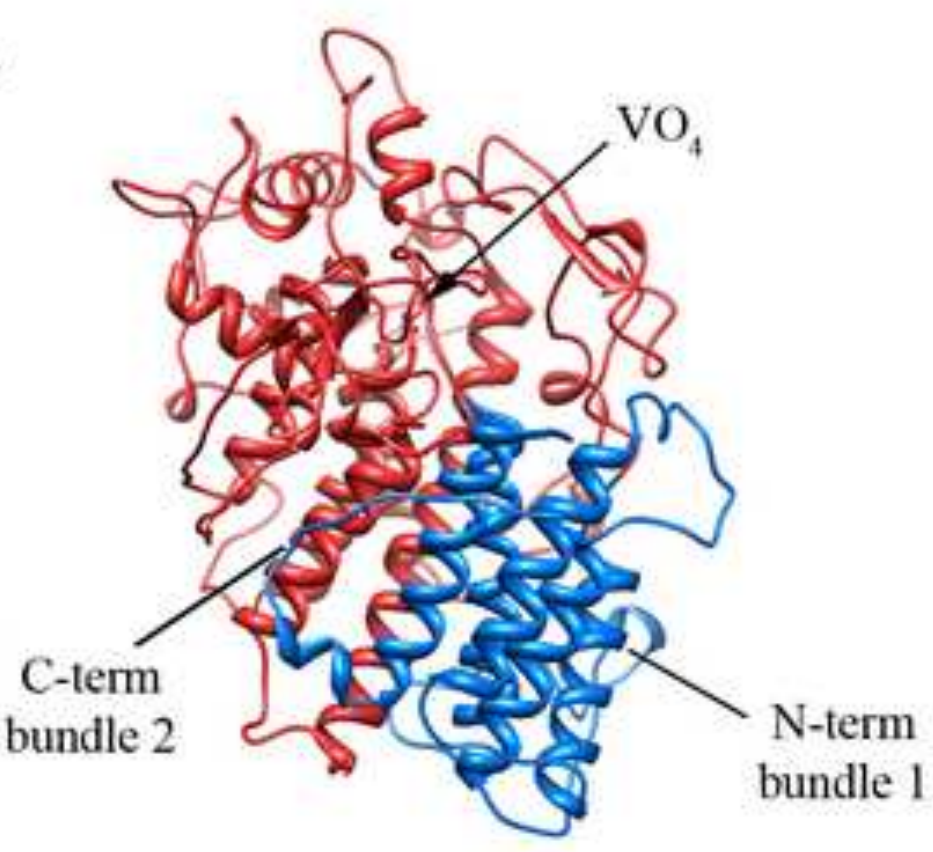

C

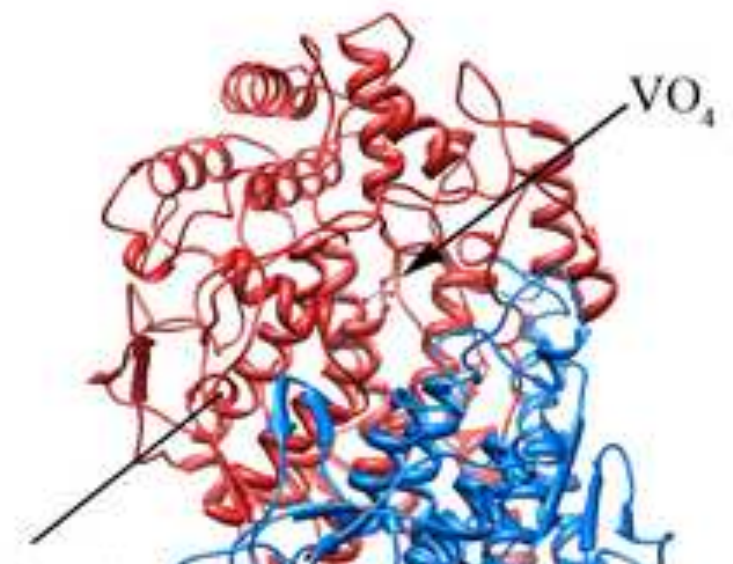

C-term bundle tors

(monomer 1) $\{130$

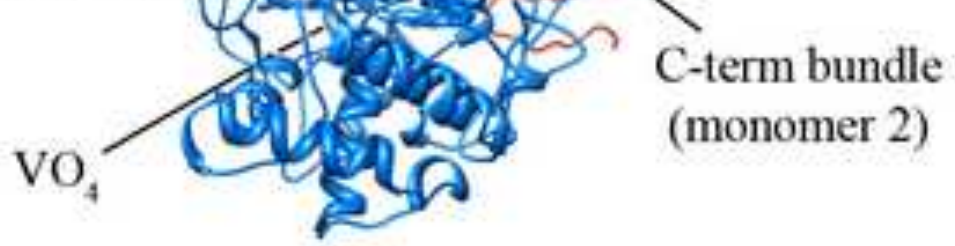

B
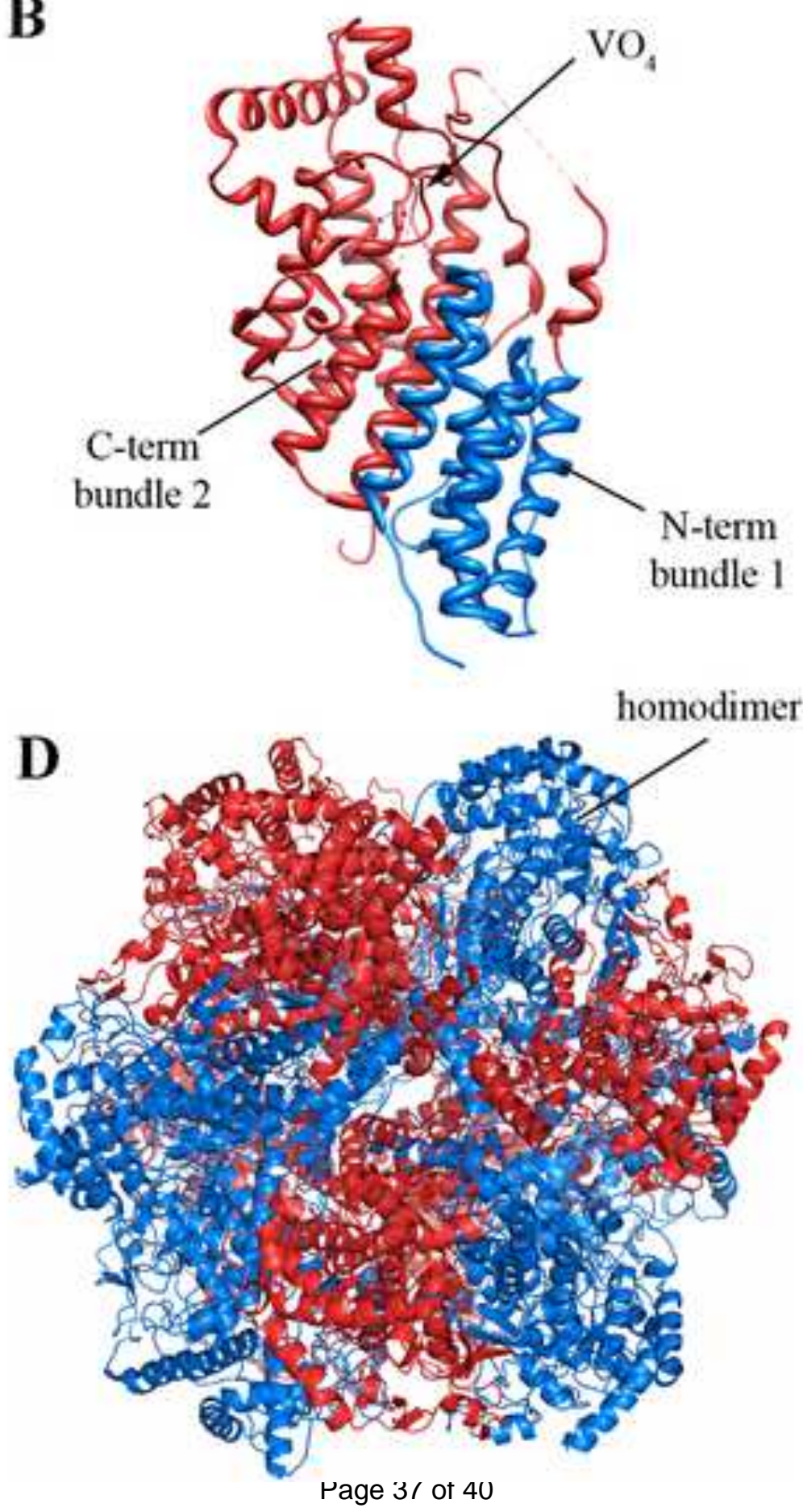
A

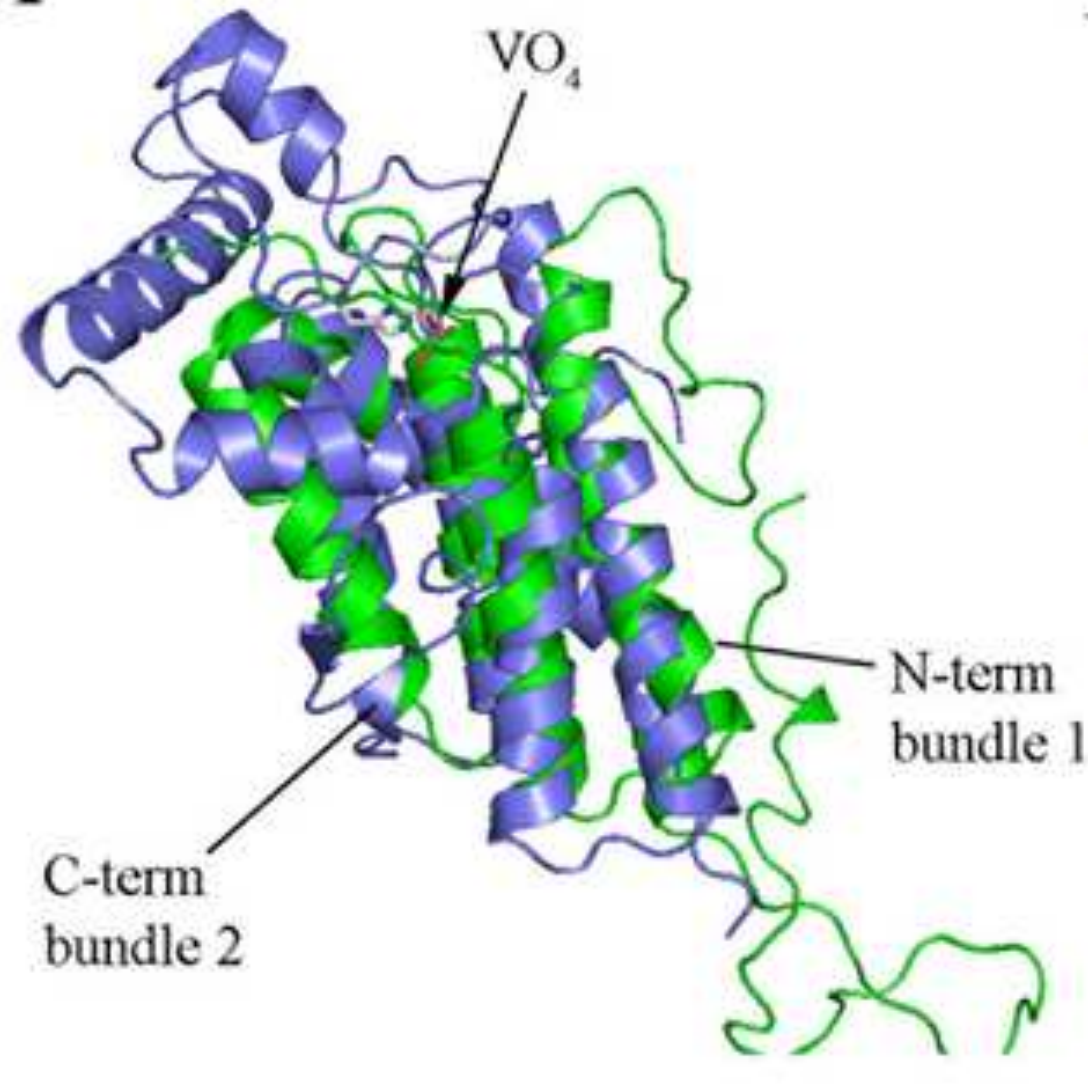

B

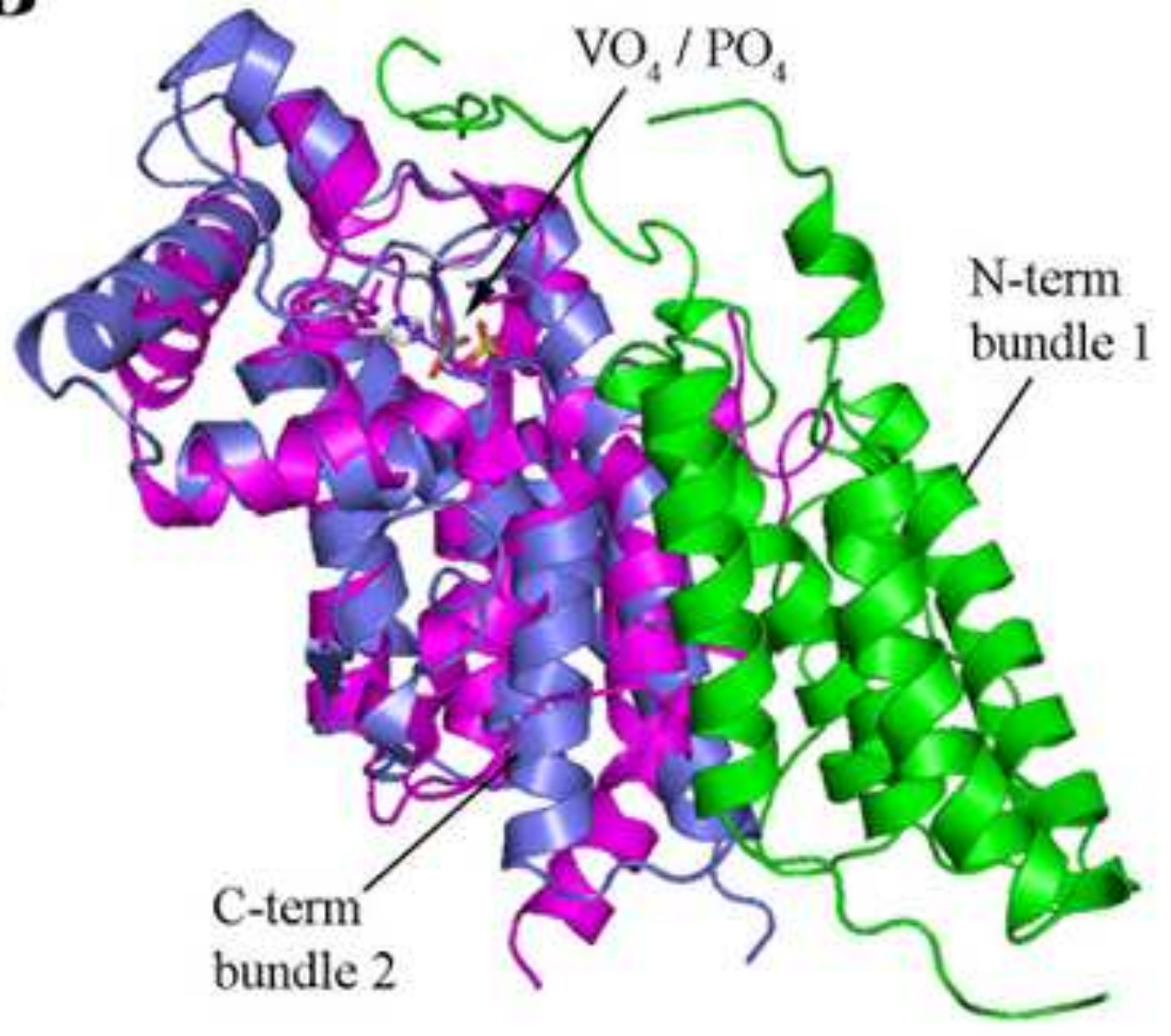




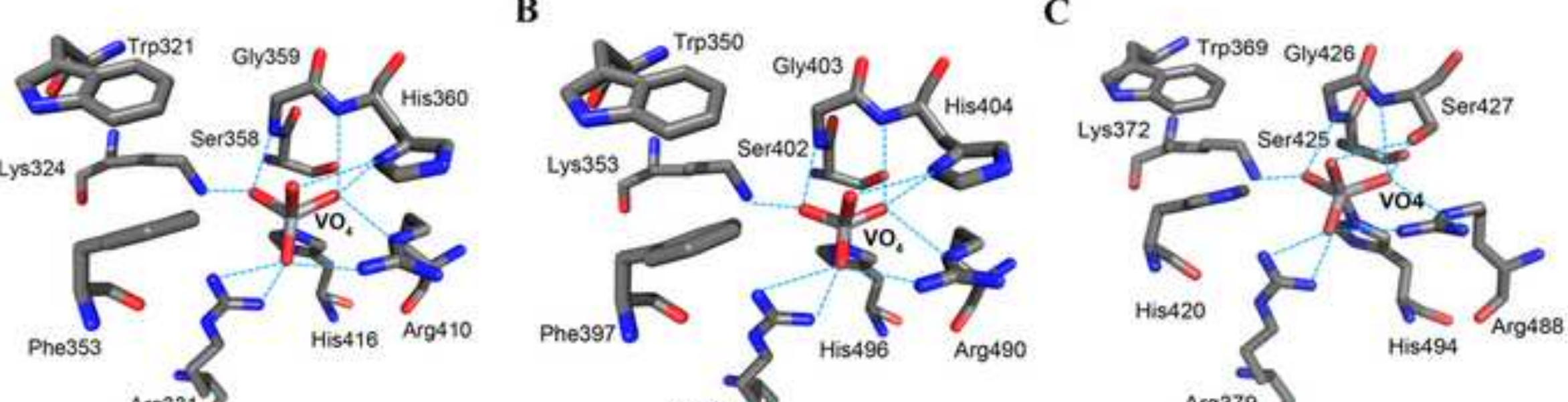

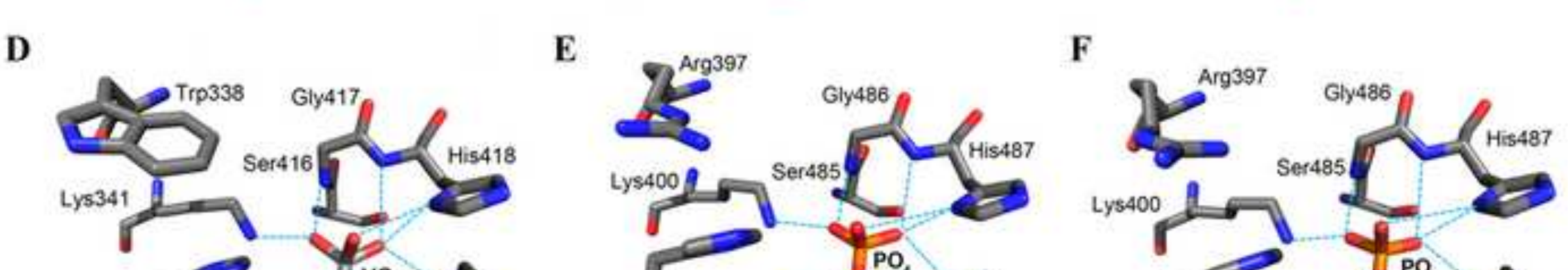

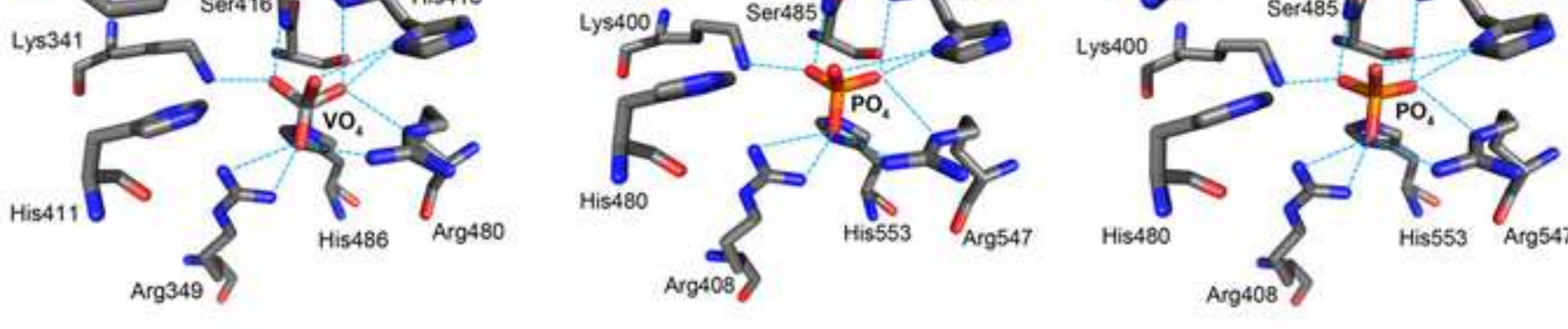



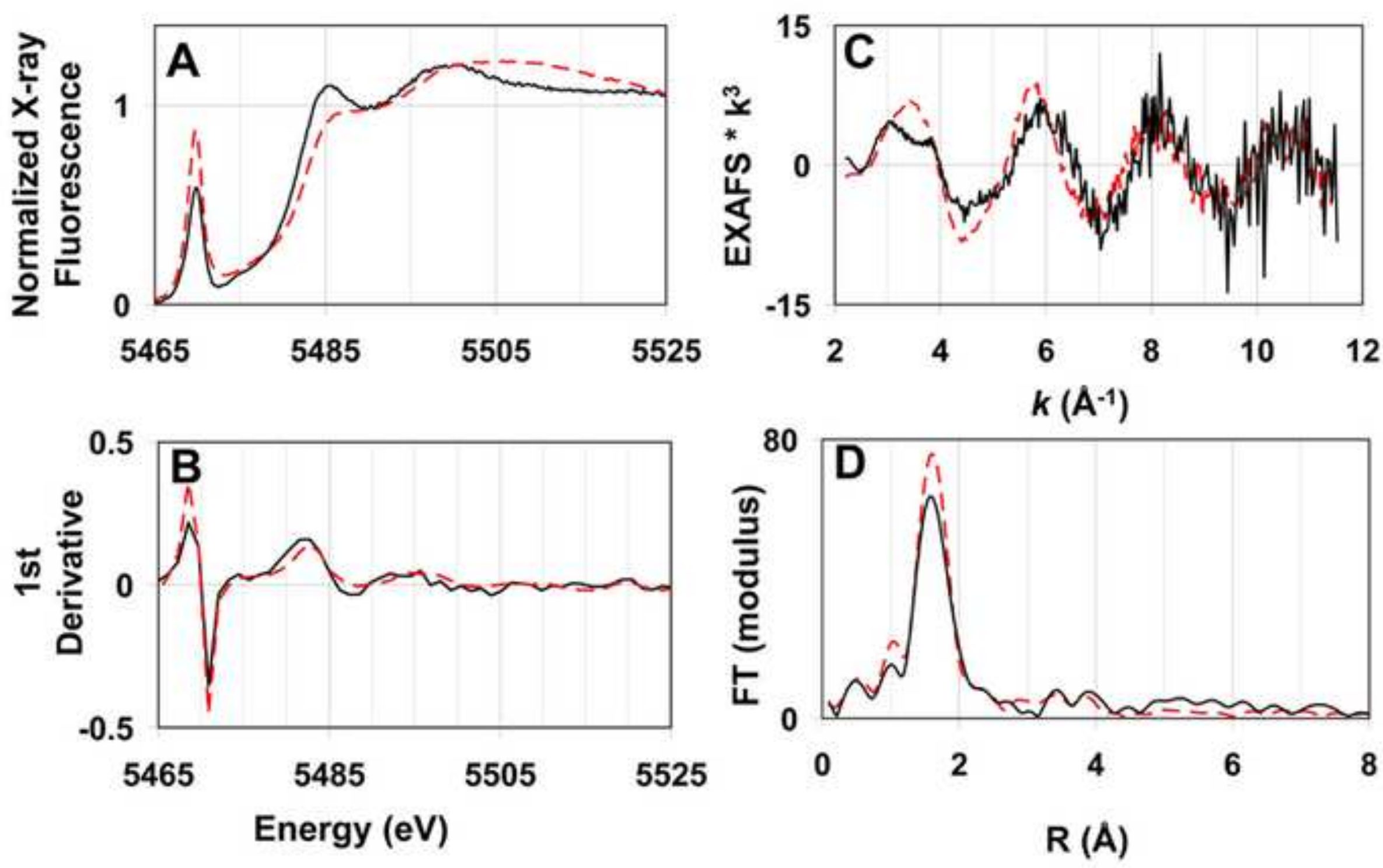